Research Article

\title{
Microstructure, Mechanical, and Electrical Properties and Corrosion Analysis of Lead-Free Solder CSI Joints on Cu Substrate Using Novel Concentrated Solar Energy Soldering (CSES) Method
}

\author{
Pushkaraj D. Sonawane $\mathbb{D}^{1},{ }^{1}$ V. K. Bupesh Raja $\mathbb{D}^{2},{ }^{2}$ and Manoj Gupta $\mathbb{D}^{3}$ \\ ${ }^{1}$ Department of Mechanical Engineering, Sathyabama Institute of Science and Technology (Deemed to be University), \\ Chennai 600119, India \\ ${ }^{2}$ School of Mechanical Engineering, Sathyabama Institute of Science and Technology (Deemed to be University), \\ Chennai 600119, India \\ ${ }^{3}$ Department of Mechanical Engineering, National University of Singapore, Singapore \\ Correspondence should be addressed to V. K. Bupesh Raja; bupeshvk@gmail.com
}

Received 14 December 2019; Accepted 6 March 2020; Published 26 March 2020

Academic Editor: Alicia E. Ares

Copyright ( $\odot 2020$ Pushkaraj D. Sonawane et al. This is an open access article distributed under the Creative Commons Attribution License, which permits unrestricted use, distribution, and reproduction in any medium, provided the original work is properly cited.

In this study, "Concentrated Solar Energy (CSE)" is applied for soldering and is named as the "Concentrated Solar Energy Soldering (CSES) technique." Lead-free solders are used for comparing novel CSES technique solder joints with CSI (Conventional Soldering Iron) solder joints. Tensile strength, bending/flexural strength, microhardness, electrical resistivity, fractography, optical microstructures, SEM microstructures, and EDS analysis were used to compare CSES solder joints with CSI solder joints. The salt spray test (SST) was used for corrosion analysis of CSES and CSI solder joints. Experimental results reveal that the tensile response, bending strength, and microhardness of the CSES solder joints were almost equal to those of the CSI solder joints. It was observed that after corrosion, the tensile strength, bending strength, and microhardness for CSES and CSI solder joints reduced. CSES solder joints were found to be slightly better than CSI solder joints for electrical resistivity. Electrical resistivity for all the cases studied was found to increase slightly after corrosion. Interfacial integrity and effect of corrosion were clearly observed on CSES and CSI solder joint microstructures. The intermetallic compounds (IMC) formed in case of CSES solder joints were found to be having slightly less thickness than that of CSI solder joints. The results demonstrate CSES technique as a green technology and a potential substitute to the CSI method.

\section{Introduction}

A proper solder material and soldering method ensures good integration of mechanical and electric connections for electronic devices. SnPb solders were used for the past few decades due to their good mechanical and corrosion resistance properties. Advantages of being economical and good wettability added to their extensive use [1-7]. In July 2006, the European Reduction of Hazardous Substances (RoHS) banned lead [8, 9]. Since then, the development of lead-free solder alloy has gained importance. As a result, the $\mathrm{Sn}-\mathrm{Ag}-\mathrm{Cu}$ (SAC) solder is developed as an alternative solder alloy. This solder alloy with different compositions has found wide acceptance in the industry owing to the amalgamation of good solder properties accompanied by reasonably decent mechanical properties [10-12].

As a result of their ease of usage, acceptable creep rate, and good solderability, joint strength, and ductility, SAC solders are currently used widely in industries. However, the main disadvantage is the solder cost. Because of the $\mathrm{Ag}$ content, the price of the SAC solder is high. Changing Ag price causes fluctuations in the alloy cost. Sn-Cu-based solders are less expensive alternatives to SAC 305 solders, and a number of options with different additives are available. Even SAC solders with less than $1 \% \mathrm{Ag}$ content are also good alternatives to SAC 305 [2]. 
Corrosion of the solder joint is a major concern in soldering applications [13]. Many researchers are working on corrosion analysis of solder joints. A decrease in the life of electronic devices was found to be associated with pitting corrosion in solder joints [14].

Due to scarcity of fossil fuel, numerous researchers are concentrating on an alternative energy source [15-17]. Concentrated Solar Energy (CSE) using Fresnel lens was found to be viable $n$ surface hardening of steel (see Figure 1) $[18,19]$.

Concentrated Solar Energy (CSE) is a potent substitute for material processing. It is being used in a variety of material processing applications [20]. Most of the literature available related to CSE for material processing are on different solar collectors. For Fresnel lens for material processing, there is very less work available, though they offer consistent flux on the absorber [21]. It was found in the literature that nobody has worked on soldering using CSE. The motivation for this research is to apply CSE (by using Fresnel lens) to lead-free soldering applications and establish this green technology.

\section{Experimental Procedure}

2.1. Concentrated Solar Energy Soldering (CSES) Experimental Setup. In this study, concentrating solar energy is applied for soldering and named as the "Concentrated Solar Energy Soldering (CSES) technique" [22]. The CSES setup has Fresnel lens of $470 \mathrm{~mm}$ in diameter for concentrating solar energy, supported by the base frame (see Figure 2).

Soldering fixture was movably fixed on a base frame below the Fresnel lens as shown in Figure 3. Focal length was adjusted to get the desired temperature of $370^{\circ} \mathrm{C}$ at a focal point to heat the solder wire to enable soldering. Soldering fixture was provided the arrangement to fix and adjust the proper gap between the substrates for soldering to get a spot size of $0.6 \mathrm{~mm}$ [22].

Two-axis solar tracking was achieved with sensors, motors, and controller unit. Figure 4 shows the CSES experimental setup.

The CSES technique discussed in this work is patented with the patent application no: 201721009049 [23] and can be used in remote areas and even space to solder various components, circuits, etc.

\subsection{Conventional Soldering Iron (CSI) Soldering Experimental} Setup. SARA 71, a proportional integral derivative (PID) controlled soldering station by SARA Mechatronics, was used for "Conventional Soldering Iron (CSI)." It has the temperature range of $150^{\circ} \mathrm{C}$ to $480^{\circ} \mathrm{C}$. Special fixture was made for CSI soldering to hold the $\mathrm{Cu}$ substrates properly and ensure the gap between them as $0.8 \mathrm{~mm}$. The temperature of soldering iron can be adjusted in the soldering station.

2.3. Solder and Substrate Materials. In this study, Alpha Assembly Solutions' commercial lead-free solders SAC305, SACX0307, and 99C and one lead -containing solder $\mathrm{SnPb}$

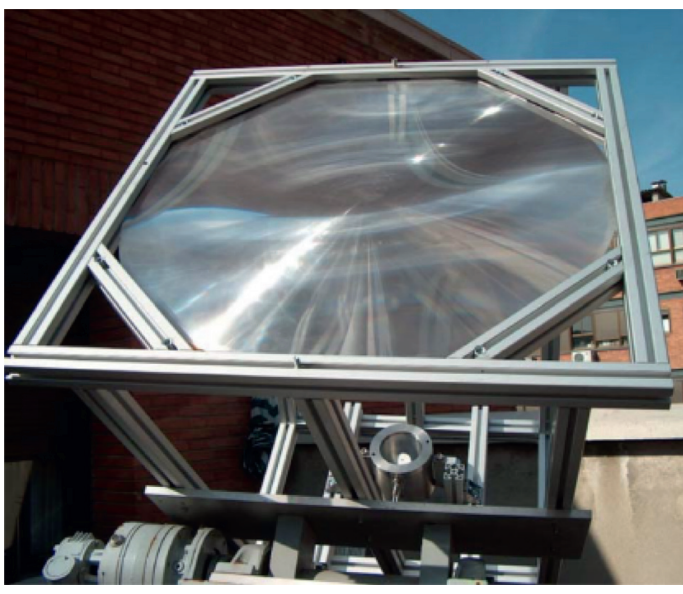

Figure 1: Fresnel installation at CENIM [18].

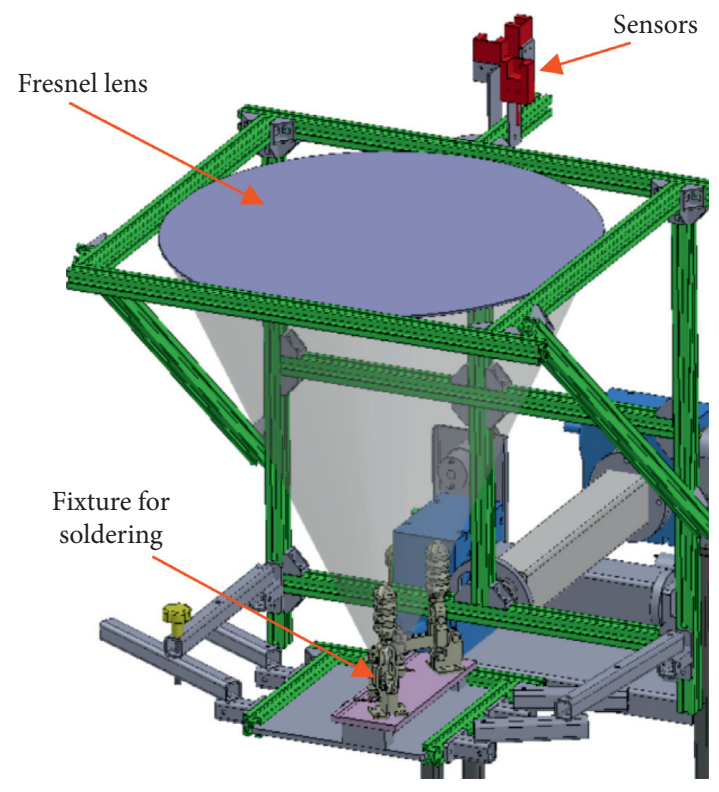

FIGURE 2: Virtual prototype of the experimental setup of "Concentrated Solar Energy Soldering" (CSES) technique.

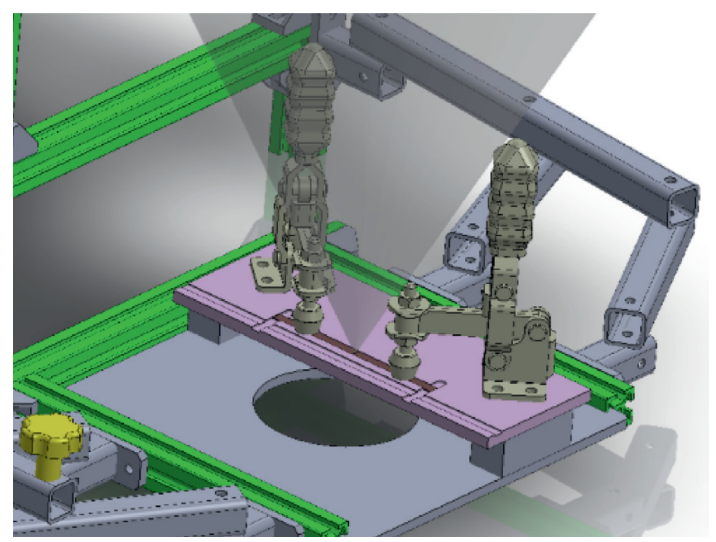

FIgURE 3: Virtual prototype of special fixture for soldering with "Concentrated Solar Energy Soldering (CSES)" technique. 


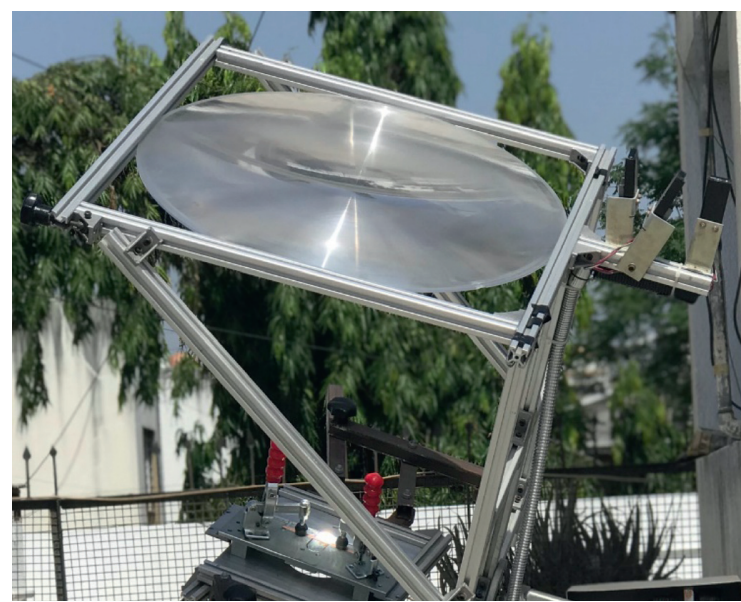

(a)

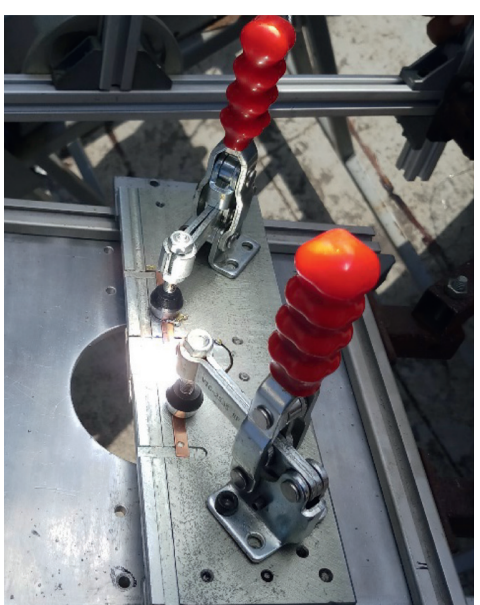

(b)

Figure 4: “Concentrated Solar Energy Soldering (CSES)" experimental setup.

were used for experimentation. All the solders contained $2.2 \%$ flux. Copper substrates used in this study had a purity level of $99.9 \% \mathrm{Cu}$. Details for solder material contents are given in Table 1.

2.4. Substrate Dimensions. Different researchers used substrate dimensions such as length $=50 \mathrm{~mm}$; width $=5 \mathrm{~mm}$; thickness $=1 \mathrm{~mm}$ (see Figure 5). With these substrate dimensions, a butt joint of length $=1 \mathrm{~mm}$; width $=5 \mathrm{~mm}$ was obtained [24].

For this study, the dimensions of the $\mathrm{Cu}$ substrate used were length $=50 \mathrm{~mm}$; width $=5 \mathrm{~mm}$; thickness $=0.5 \mathrm{~mm}$. As electronic industries use soldering for microjoining [25], in this study, it was proposed to study a microbutt joint of length $=0.8 \mathrm{~mm}$; width $=5 \mathrm{~mm}$; thickness $=0.5 \mathrm{~mm}$.

A butt joint was successfully obtained with CSES technique by using SAC305 and SACX0307 lead-free solders. The initial results achieved with CSES technique were promising [22].

2.5. Sample Preparation for Testing. For different mechanical tests (tensile test, bending test, and microhardness test) and electrical resistivity test, the $\mathrm{Cu}$ substrate of length $=50 \mathrm{~mm}$; width $=5 \mathrm{~mm}$; thickness $=0.5 \mathrm{~mm}$ was prepared. SAC 305 , SACX0307, 99C, and $\mathrm{SnPb}$ solders were used to obtain a butt joint between two $\mathrm{Cu}$ substrates with the CSES technique and CSI method. A microbutt joint of length $=0.8 \mathrm{~mm}$; width $=5 \mathrm{~mm}$; thickness $=0.5 \mathrm{~mm}$ was obtained. In the air, the solder joint was allowed to solidify. Excess solder on $\mathrm{Cu}$ plates was removed by grounding and polishing after solidification. Prior to different mechanical testing, 1200 grit SiCp paper $[26,27]$ was used to further ground the CSES and CSI solder joints to take out extra solder at the edges.

2.6. Tensile Test. The tensile tests were conducted at room temperature with a crosshead speed of $2 \mathrm{~mm} / \mathrm{min}$. Results were averaged for five CSES and CSI solder joints. The ASTM test standard E8M-09 was used to determine the tensile strength of the CSES and CSI solder joints [26, 28, 29].
TABLe 1: Solder details.

\begin{tabular}{lcccc}
\hline & Sn (wt.\%) & $\mathrm{Cu}$ (wt.\%) & $\mathrm{Ag}$ (wt.\%) & $\mathrm{Pb}$ (wt.\%) \\
\hline SAC305 & 96.5 & 0.5 & 3 & - \\
SACX0307 & 99 & 0.7 & 0.3 and X alloys & - \\
99C & 99.3 & 0.7 & - & - \\
$\mathrm{SnPb}$ & 63 & - & - & 37 \\
\hline
\end{tabular}

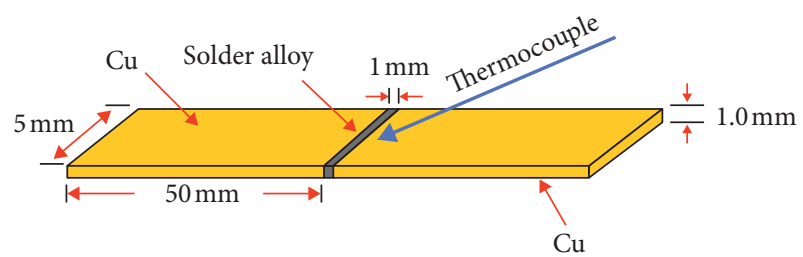

FIgURE 5: Schematic diagram of the $\mathrm{Cu} / \mathrm{SAC} 305 / \mathrm{Cu}$ butt joint achieved with CSES technique [24].

2.7. Fractography. The mode of failure exhibited by CSES and CSI solder joints was determined by fractography investigation. An optical microscope was used to take fractographs on tensile fracture surfaces.

2.8. Bending/Flexural Test. At room temperature, the bending/flexural tests were conducted with a crosshead speed of $2 \mathrm{~mm} / \mathrm{min}$. The results were averaged after testing five CSES and CSI solder joints. The ASTM D 790-03 standard was used for finding the bending/flexural properties of the CSES and CSI solder joints.

2.9. Microhardness Test. The microhardness tests on CSES and CSI solder joints were conducted at room temperature. The Vickers pyramidal diamond indenter with a facing angle of $136^{\circ}$ was used for the test. A digital microhardness tester was used to measure Vickers microhardness. For the testing, a $10 \mathrm{gf}$ indenting load and dwell time of 15 seconds were used. The results of five CSES and CSI solder joints were averaged to get microhardness of the CSES and CSI solder 
joints. Polished CSES and CSI solder joints were used for measuring microhardness according to the ASTM standard E384-99 [30].

2.10. Electrical Resistivity Test. In this study, electrical resistivity tests were conducted at room temperature and with a probe spacing of $1.5875 \mathrm{~mm}$. A four-point probe method $[26,31]$ was used to check the electrical resistivity of CSES and CSI soldered joints, as shown in Figure 6.

At least five CSES and CSI solder joints were tested, and the results were averaged. The electrical resistivity properties of the CSES and CSI solder joints were determined as per the ASTM standard ASTM B193-16 [26].

2.11. Microstructural Characterization. Microstructural characterization investigation was performed on metallographically polished extruded CSES and CSI solder joints to examine the morphological features of grains and second phases. Etching was done to observe the grain boundaries. The etching solution was prepared by mixing 5 vol. $\% \mathrm{HCl}$ in ethanol [32]. Initially, an optical microscope was used to take the microstructure at $400 \times$. Then, to reveal the microstructure at the interface of the solder and the substrate, it was taken at a higher magnification using SEM. The composition of the elements was determined with the help of EDS attached with SEM machine.

2.12. Salt Spray Test. Salt spray test (SST) was used for corrosion analysis of CSES and CSI joints. The SST is a widely used technique for estimating corrosion resistance of soldered joints [13, 33-35]. In this study, in an enclosed chamber at $35^{\circ} \mathrm{C}, \mathrm{CSES}$ and CSI solder joints were exposed to a fog created from a $5 \mathrm{wt} . \% \mathrm{NaCl}$ solution for 96 hours. The salt spray test was conducted as per ASTM B-117 [13, 33, 34]. Tensile strength, fractography, bending/flexural strength, microhardness, electrical resistivity, microstructural characterization, and EDS analysis were done for these corroded samples. The properties before and after corrosion were analysed for CSES and CSI solder joints.

\section{Results and Discussion}

3.1. Tensile Strength. The experimental results of tensile testing are presented in Table 2 and represented graphically in Figure 7. The results show that the tensile response of the CSES solder joints is almost equal to that of the CSI solder joints. The results obtained show that SAC305 CSES (before and after corrosion) solder joints exhibited higher tensile strength than SACX0307 and 99C CSES (before and after corrosion) solder joints. SAC305 CSES (before and after corrosion) solder joints also exhibited marginally higher average tensile strength than SnPb CSES (before and after corrosion) solder joints. These results are also found to be in a good agreement with earlier research [36]. It was observed that, after corrosion, the tensile strength for CSES and CSI solder joints reduced. This is attributed to interdendritic or pitting corrosion effect on the CSES and CSI solder joints.

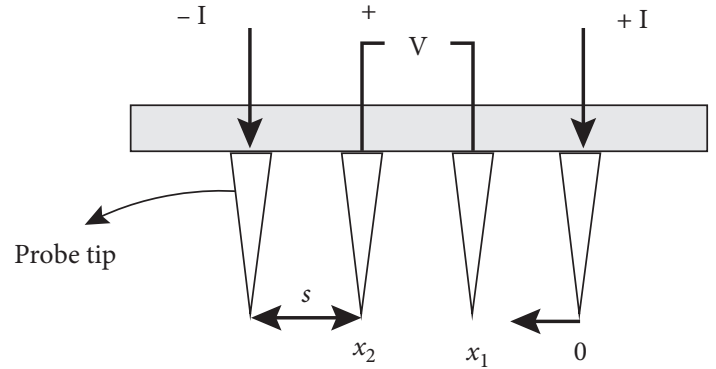

FiguRE 6: Four-point probe configuration method [26].

3.2. Fractography. The representative fractographs of the solder joints made of different solders before and after corrosion are shown in Figure 8. Fractography images show that the fracture was relatively ductile in nature and was always found at the solder portion of solder joints and not near the substrates, which were joined. Fractographs of CSES technique solder joints (before and after corrosion) of SAC305, SACX0307, 99C, and SnPb fracture edges show (see Figures 8(a), 8(c), 8(e), 8(g), 8(i), 8(k), 8(m), and 8(o)) relatively flat nature in the soldered area and indicate sound condition. But, fractographs of the CSI method solder joints (before and after corrosion) of SAC305, SACX0307, 99C, and $\mathrm{SnPb}$ fracture edge show (see Figures $8(\mathrm{~b}), 8(\mathrm{~d}), 8(\mathrm{f}), 8(\mathrm{~h}), 8(\mathrm{j}), 8(\mathrm{l}), 8(\mathrm{n})$, and $8(\mathrm{p}))$ relatively fine nature with indication of microporosities (see Figure 8), which reduces the tensile and bending strength of solder joints.

3.3. Bending/Flexural Strength. Table 3 shows the experimental results of the bending/flexural test. The results revealed that the bending/flexural strength of the CSES solder joints is comparable with that of CSI solder joints. It was observed that SAC305 CSES (before corrosion) solder joints had more bending/flexural strength than SACX0307, 99C, and SnPb CSES (before and after corrosion) solder joints. Also, SAC305 CSI (before corrosion) solder joints were found to have more bending/flexural strength than SACX0307, 99C, and SnPb CSI (before and after corrosion) solder joints. With corrosion, bending/flexural strength for CSES and CSI solder joints was found to be reducing (see Figure 9).

3.4. Microhardness. The microhardness test results of CSES and CSI solder joints are given in Table 4 . The results of CSES solder joints revealed that the microhardness of the CSES and CSI solder joints is almost similar. It was observed that SAC305 CSES (before corrosion) solder joints had higher average microhardness than SACX0307, 99C, and $\mathrm{SnPb}$ CSES (before and after corrosion) solder joints. Also, SAC305 CSI (before corrosion) solder joints exhibited higher average microhardness than SACX0307, 99C, and $\mathrm{SnPb} \mathrm{CSI}$ (before and after corrosion) solder joints. The reduction in microhardness for CSES and CSI solder joints was observed after corrosion (see Figure 10). 
TABLE 2: Tensile strength of CSES and CSI solder joints (before and after corrosion).

\begin{tabular}{|c|c|c|c|c|c|c|c|c|}
\hline \multirow{2}{*}{$\begin{array}{l}\text { Solder } \\
\text { material }\end{array}$} & \multicolumn{2}{|c|}{ CSES (before corrosion) } & \multicolumn{2}{|c|}{ CSI (before corrosion) } & \multicolumn{2}{|c|}{ CSES (after corrosion) } & \multicolumn{2}{|c|}{ CSI (after corrosion) } \\
\hline & $\begin{array}{c}\text { Tensile strength } \\
(\mathrm{MPa})\end{array}$ & $\begin{array}{c}\text { Std } \\
\text { devi. }\end{array}$ & $\begin{array}{l}\text { Tensile strength } \\
(\mathrm{MPa})\end{array}$ & $\begin{array}{c}\text { Std } \\
\text { devi. }\end{array}$ & $\begin{array}{c}\text { Tensile strength } \\
(\mathrm{MPa})\end{array}$ & $\begin{array}{c}\text { Std } \\
\text { devi. }\end{array}$ & $\begin{array}{l}\text { Tensile strength } \\
(\mathrm{MPa})\end{array}$ & $\begin{array}{c}\text { Std } \\
\text { devi. }\end{array}$ \\
\hline SAC305 & 46.894 & 1.1523 & 45.182 & 1.1643 & 39.895 & 1.4523 & 38.993 & 1.1723 \\
\hline SACX0307 & 35.207 & 1.1943 & 34.154 & 2.1943 & 28.861 & 1.2943 & 27.923 & 1.2943 \\
\hline $99 \mathrm{C}$ & 31.904 & 1.2333 & 30.189 & 1.5333 & 25.243 & 1.5333 & 23.378 & 1.2633 \\
\hline $\mathrm{SnPb}$ & 44.832 & 1.2863 & 43.987 & 1.5863 & 36.986 & 1.4863 & 35.762 & 1.3863 \\
\hline
\end{tabular}

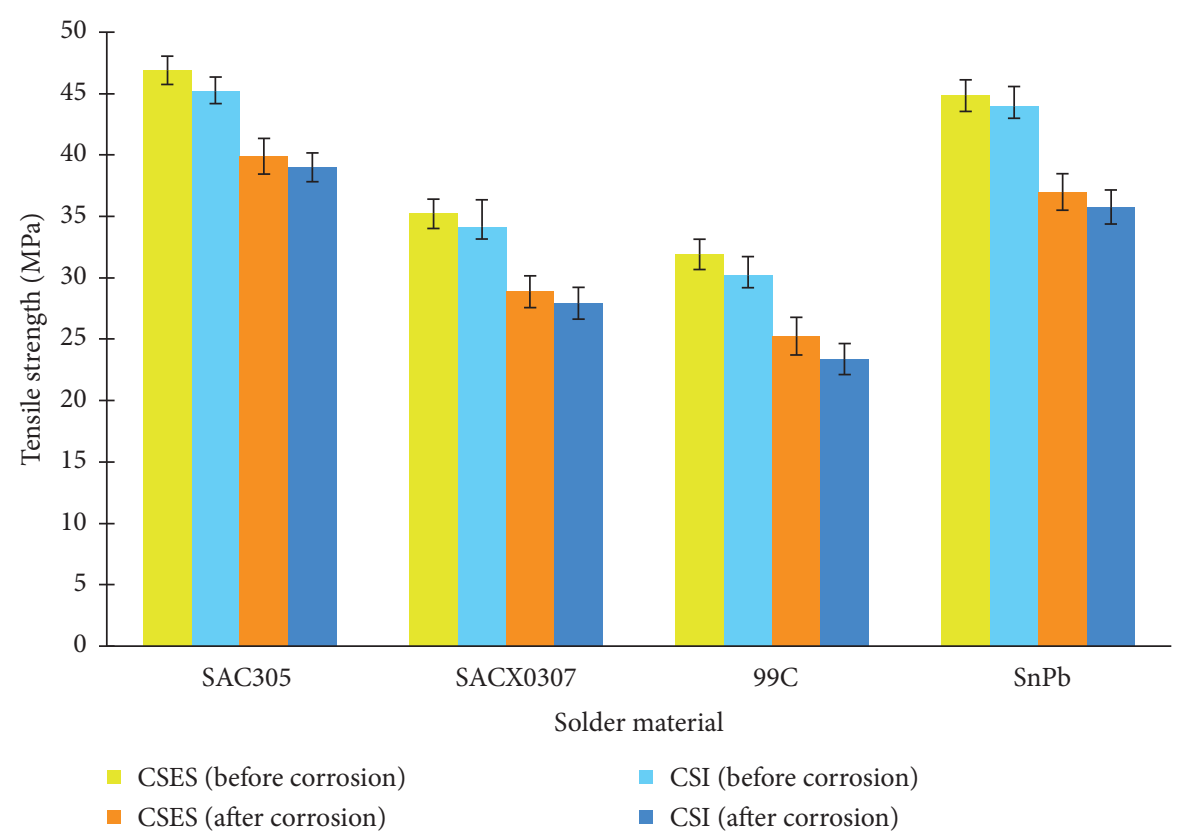

FIGURE 7: Plot of tensile strength of different lead-free and SnPb solder joints achieved with the CSES technique and CSI method (before and after corrosion).

3.5. Electrical Resistivity. Table 5 presents the experimental results of electrical resistivity of CSES and CSI solder joints which were compared with the bare copper substrate. The results plotted, as shown in Figure 11, showed that the electrical resistivities of the CSES (before and after corrosion) solder joints were slightly better than those of CSI (before and after corrosion) solder joints. Electrical resistivity of SAC305 CSES (before and after corrosion) solder joints was observed to be better than that ofvSACX0307, 99C, and SnPb CSI (before and after corrosion) solder joints. The corrosion effect on electrical resistivity can be clearly seen from the results obtained. After corrosion, electrical resistivity for all the cases studied was found to be slightly increased and this was consistent with the observation of other researchers [37].

3.6. Microstructural Characterization. Figures 12 and 13 show optical and SEM micrographs, respectively, for different lead-free and $\mathrm{SnPb}$ solder joints achieved with the CSES technique and CSI method (before and after corrosion). Optical and SEM micrographs at solder portion of different lead-free and $\mathrm{SnPb}$ solder joints achieved with the CSES technique and CSI method (before and after corrosion) are shown in Figures 14 and 15, respectively.

The microstructure of $\mathrm{Cu} / \mathrm{SAC} 305 / \mathrm{Cu}$ CSES (before corrosion) solder joint shows coarse dendritic grains of the tin-rich solid solution in a eutectic matrix (see Figures 12(a), 13(a), 14(a), and 15(a)). As in the case of CSES solder joints, continuous heat was provided to join two substrates, which melts the solder faster but solidifies slower compared to the CSI solder joint. The coarse microstructure was thus obtained.

As shown in Figures 12(b), 13(b), 14(b), and 15(b), the microstructure of the $\mathrm{Cu} / \mathrm{SAC} 305 / \mathrm{Cu}$ CSI (before corrosion) solder joint shows fine dendritic grains of the tin-rich solid solution in a eutectic matrix with microporosity. Microporosity observed has reduced the tensile and bending strength of the solder joint when compared with that of the $\mathrm{Cu} / \mathrm{SAC} 305 / \mathrm{Cu}$ CSES (before corrosion) solder joint. As there was intermittent heat provided to join the two substrates, in case of CSI joints, it takes more time for solder to melt and faster solidification is realized compared with the CSES solder joint, leading to a refined microstructure.

The microstructure of the Cu/SAC305/Cu CSES (after corrosion) solder joint shows coarse dendritic grains of the 


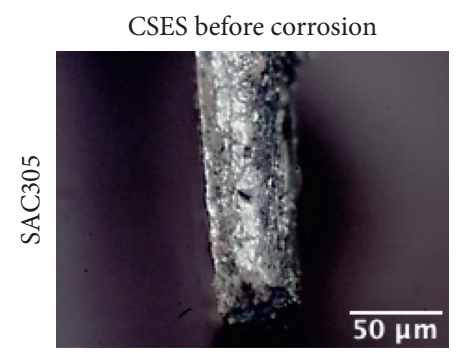

(a)

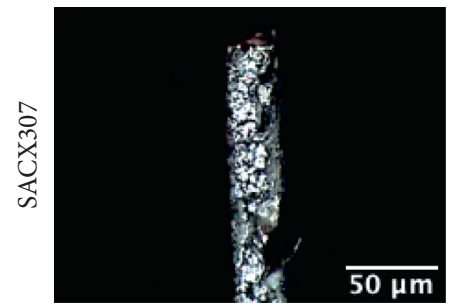

(e)

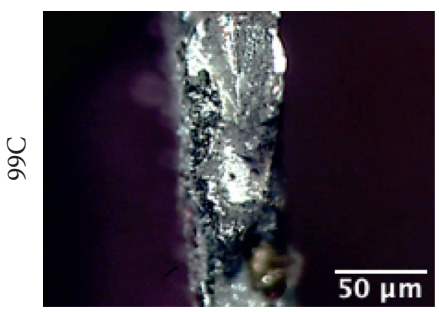

(i)

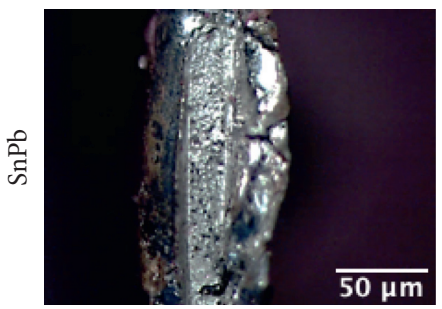

(m)
CSI before corrosion

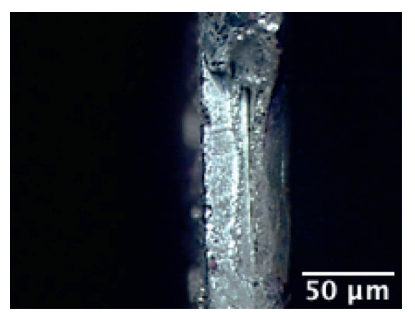

(b)

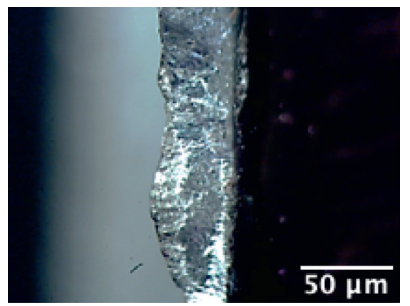

(f)

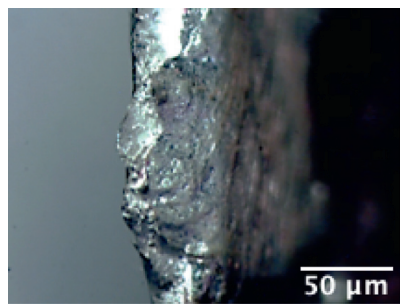

(j)

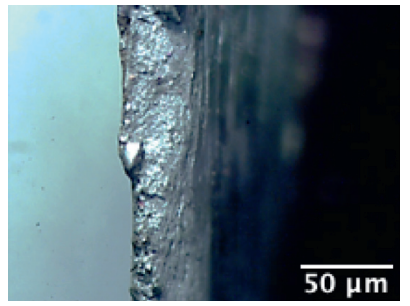

(n)
CSES after corrosion

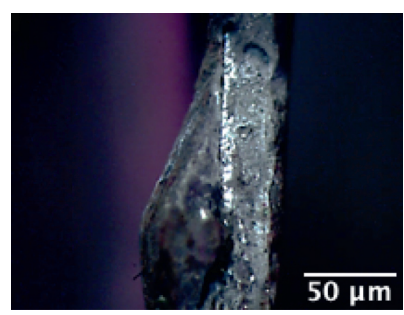

(c)

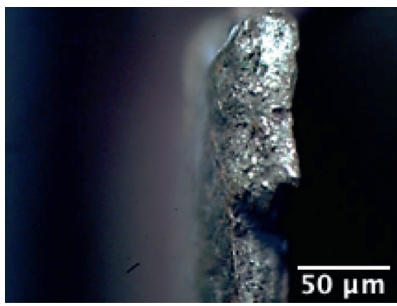

(g)

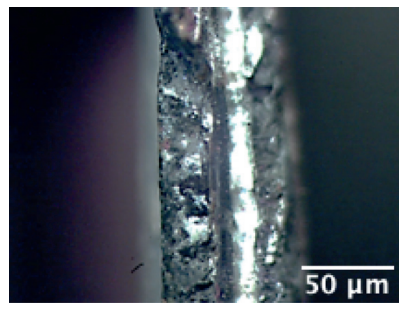

(k)

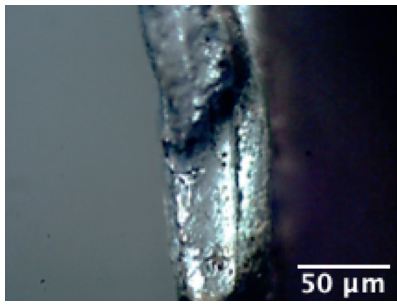

(o)
CSI after corrosion

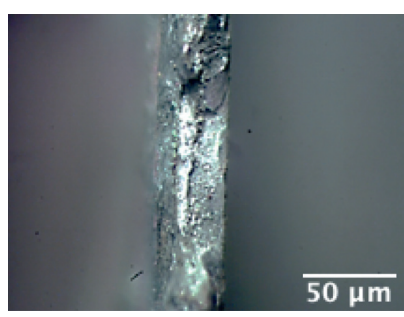

(d)

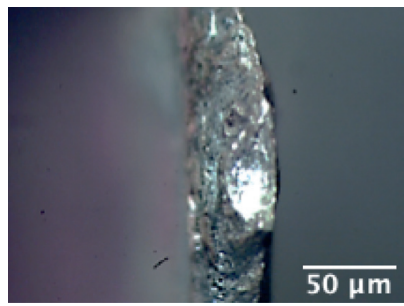

(h)

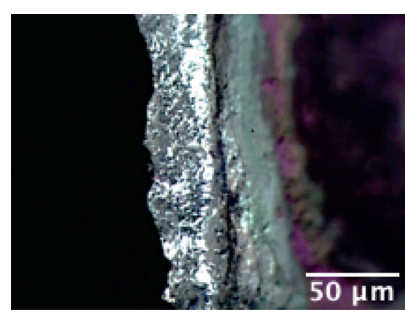

(1)

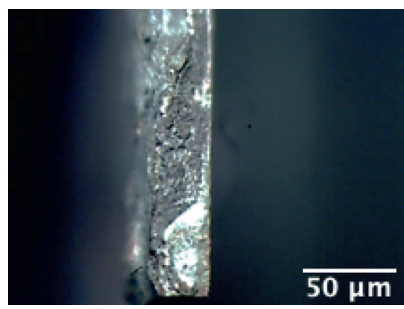

(p)

FIGURE 8: Representative fractographs of solder joints created using CSES and CSI methods (before and after corrosion).

tin-rich solid solution in a eutectic matrix (see Figures 12(c), $13,14(\mathrm{c})$, and $15(\mathrm{c}))$. The pitting corrosion was observed in the solder joint leading to reduced tensile and bending strength of the solder joint when compared with that of the $\mathrm{Cu} / \mathrm{SAC} 305 / \mathrm{Cu}$ CSES (before corrosion) solder joint (see Tables 2 and 3 ).

Fine dendritic grain microstructure of the tin-rich solid solution in a eutectic matrix with microporosity was observed for the $\mathrm{Cu} / \mathrm{SAC} 305 / \mathrm{Cu}$ CSI (after corrosion) solder joint (see Figures 12(d), 13(d), 14(d), and 15(d)). Tensile and bending strength of the solder joint compared with the $\mathrm{Cu} /$ SAC305/Cu CSI (before corrosion) solder joint were found to be reduced because of microporosity and pitting corrosion which were observed to have occurred in the solder joint (see Tables 2 and 3 ).

The microstructure of the Cu/SACX0307/Cu CSES (before corrosion) solder joint shows coarse dendritic grains of the tin-rich solid solution in a eutectic matrix (see Figures 12(e), 13(e), 14(e), and 15(e)).
As shown in Figures 12(f), 13(f), 14(f), and 15(f), the microstructure of the $\mathrm{Cu} / \mathrm{SACX} 0307 / \mathrm{Cu} \mathrm{CSI}$ (before corrosion) solder joint shows fine dendritic grains of the tin-rich solid solution in a eutectic matrix with microporosity. Microporosity observed has reduced the tensile and bending strength of the solder joint when compared with that of the $\mathrm{Cu} / \mathrm{SACX} 307 / \mathrm{Cu}$ CSES (before corrosion) solder joint (see Tables 2 and 3).

The microstructure of the Cu/SACX0307/Cu CSES (after corrosion) solder joint shows coarse dendritic grains of the tin-rich solid solution in a eutectic matrix (see Figures $12(\mathrm{~g})$, $13(\mathrm{~g}), 14(\mathrm{~g})$ and $15(\mathrm{~g}))$. The pitting corrosion was observed in the solder joint, which reduced the tensile and bending strength of the solder joint compared with that of the $\mathrm{Cu} /$ SACX307/Cu CSES (before corrosion) solder joint (see Tables 2 and 3).

Fine dendritic grains of the tin-rich solid solution in a eutectic matrix with microporosity was observed for the $\mathrm{Cu}$ / SACX0307/Cu CSI (after corrosion) solder joint (see Figures 12(h), 13(h), 14(h), and 15(h)). Tensile and bending 
TABLE 3: Bending/flexural strength of CSES and CSI solder joints (before and after corrosion).

\begin{tabular}{|c|c|c|c|c|c|c|c|c|}
\hline \multirow{2}{*}{$\begin{array}{l}\text { Solder } \\
\text { material }\end{array}$} & \multicolumn{2}{|c|}{ CSES (before corrosion) } & \multicolumn{2}{|c|}{ CSI (before corrosion) } & \multicolumn{2}{|c|}{ CSES (after corrosion) } & \multicolumn{2}{|c|}{ CSI (after corrosion) } \\
\hline & $\begin{array}{l}\text { Bending strength } \\
(\mathrm{MPa})\end{array}$ & $\begin{array}{c}\text { Std } \\
\text { devi. }\end{array}$ & $\begin{array}{c}\text { Bending strength } \\
(\mathrm{MPa})\end{array}$ & $\begin{array}{c}\text { Std } \\
\text { devi. }\end{array}$ & $\begin{array}{l}\text { Bending strength } \\
(\mathrm{MPa})\end{array}$ & $\begin{array}{c}\text { Std } \\
\text { devi. }\end{array}$ & $\begin{array}{l}\text { Bending strength } \\
(\mathrm{MPa})\end{array}$ & $\begin{array}{r}\text { Std } \\
\text { devi. }\end{array}$ \\
\hline SAC305 & 48.894 & 1.1323 & 48.294 & 1.1843 & 41.539 & 1.5523 & 40.002 & 1.2723 \\
\hline SACX0307 & 36.973 & 1.1743 & 36.73 & 1.9943 & 31.442 & 1.3943 & 30.942 & 1.3943 \\
\hline $99 \mathrm{C}$ & 34.629 & 1.2133 & 33.211 & 1.4333 & 28.381 & 1.5433 & 27.691 & 1.4633 \\
\hline $\mathrm{SnPb}$ & 46.762 & 1.2763 & 45.523 & 1.4863 & 38.482 & 1.5363 & 36.839 & 1.4863 \\
\hline
\end{tabular}

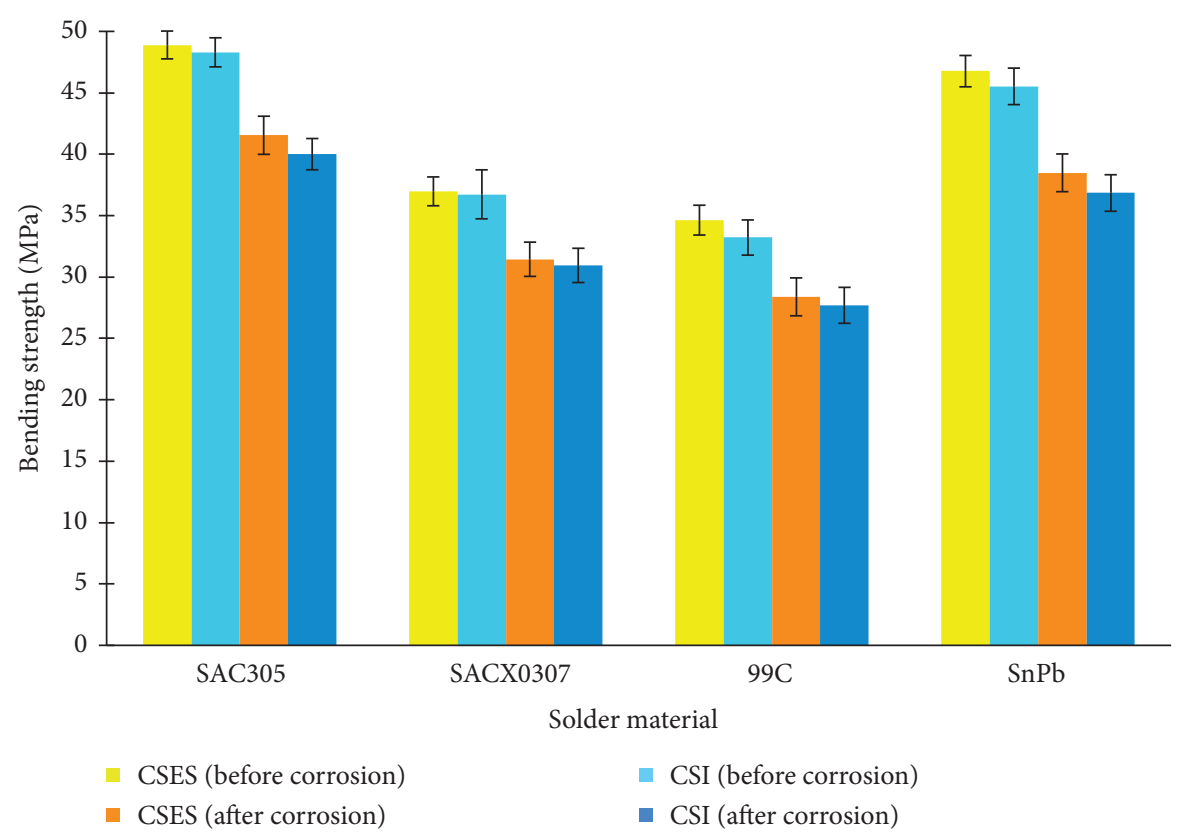

Figure 9: Plot of bending/flexural strength of different lead-free and SnPb solder joints achieved with CSES and CSI methods (before and after corrosion).

TABLE 4: Microhardness of CSES and CSI solder joints (before and after corrosion).

\begin{tabular}{|c|c|c|c|c|c|c|c|c|}
\hline \multirow{2}{*}{$\begin{array}{l}\text { Solder } \\
\text { material }\end{array}$} & \multicolumn{2}{|c|}{ CSES (before corrosion) } & \multicolumn{2}{|c|}{ CSI (before corrosion) } & \multicolumn{2}{|c|}{ CSES (after corrosion) } & \multicolumn{2}{|c|}{ CSI (after corrosion) } \\
\hline & $\begin{array}{l}\text { Microhardness } \\
(\mathrm{Hv})\end{array}$ & $\begin{array}{l}\text { Std } \\
\text { devi. }\end{array}$ & $\begin{array}{l}\text { Microhardness } \\
(\mathrm{Hv})\end{array}$ & $\begin{array}{l}\text { Std } \\
\text { devi. }\end{array}$ & $\begin{array}{l}\text { Microhardness } \\
(\mathrm{Hv})\end{array}$ & $\begin{array}{l}\text { Std } \\
\text { devi. }\end{array}$ & $\begin{array}{l}\text { Microhardness } \\
(\mathrm{Hv})\end{array}$ & $\begin{array}{r}\text { Std } \\
\text { devi. }\end{array}$ \\
\hline SAC305 & 14.98 & 0.1323 & 14.67 & 0.1843 & 12.82 & 0.2523 & 11.87 & 0.2393 \\
\hline SACX0307 & 12.86 & 0.1743 & 12.33 & 0.1943 & 11.78 & 0.2943 & 10.71 & 0.2993 \\
\hline $99 \mathrm{C}$ & 13.42 & 0.1933 & 13.19 & 0.1993 & 12.55 & 0.2433 & 11.83 & 0.2493 \\
\hline $\mathrm{SnPb}$ & 12.92 & 0.1763 & 12.33 & 0.1863 & 11.07 & 0.2363 & 10.74 & 0.2393 \\
\hline
\end{tabular}

strength of the solder joint compared with the $\mathrm{Cu} / \mathrm{SACX} 307 /$ $\mathrm{Cu}$ (before corrosion) CSI solder joint were found to reduce because of microporosity and pitting corrosion which was observed to have occurred in the solder joint (see Tables 2 and 3 ).

The microstructure of the $\mathrm{Cu} / 99 \mathrm{C} / \mathrm{Cu}$ CSES (before corrosion) solder joint shows coarse dendritic grains of the tin-rich solid solution in a eutectic matrix (see Figures 12(i), 13(i), 14(i), and 15(i)). As shown in Figures 12(j), 13(j), 14(j), and $15(\mathrm{j})$, the microstructure of the $\mathrm{Cu} / 99 \mathrm{C} / \mathrm{Cu} \mathrm{CSI}$ (before corrosion) solder joint shows the fine dendritic grains of the tin-rich solid solution in a eutectic matrix with microporosity. Microporosity observed has reduced the tensile and bending strength of the solder joint compared with that of the $\mathrm{Cu} / 99 \mathrm{C} / \mathrm{Cu} \mathrm{CSES}$ (before corrosion) solder joint (see Tables 2 and 3).

The microstructure of the $\mathrm{Cu} / 99 \mathrm{C} / \mathrm{Cu}$ CSES (after corrosion) solder joint shows coarse dendritic grains of the tin-rich solid solution in a eutectic matrix (see Figures $12(\mathrm{k})$, $13(\mathrm{k}), 14(\mathrm{k})$, and $15(\mathrm{k}))$. Severe interdendritic corrosion was observed in the solder joint, which reduced the tensile and bending strength of the solder joint compared with that of the $\mathrm{Cu} / 99 \mathrm{C} / \mathrm{Cu} \mathrm{CSES}$ (before corrosion) solder joint (see Tables 2 and 3).

Fine dendritic grains of the tin-rich solid solution in a eutectic matrix with microporosity was observed for the $\mathrm{Cu}$ / 99C/Cu CSI (after corrosion) solder joint (see Figures 12(1), 13, 14(1), and 15(1)). Tensile and bending strength of the 


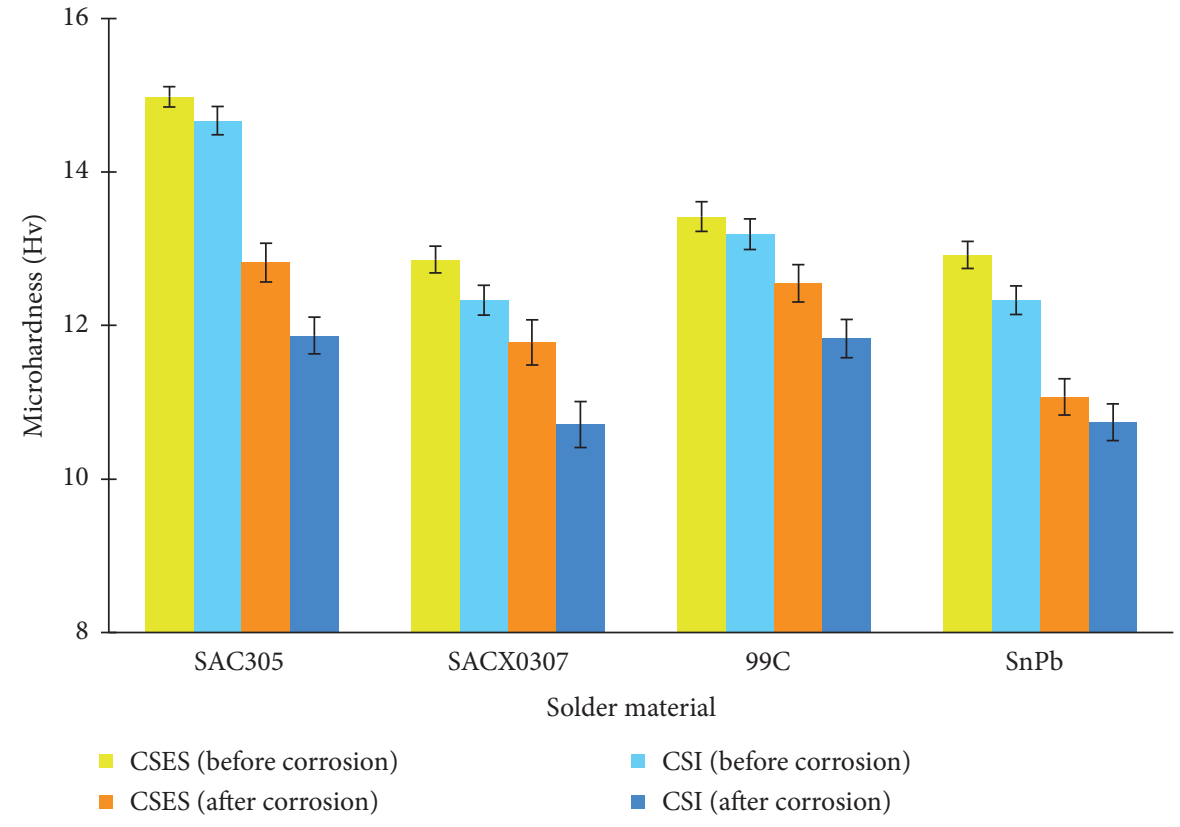

Figure 10: Plot of microhardness of different lead-free and SnPb solder joints created using CSES and CSI methods (before and after corrosion).

TABLE 5: Electrical resistivity of CSES and CSI solder joints (before and after corrosion).

\begin{tabular}{|c|c|c|c|c|c|c|c|c|}
\hline \multirow{2}{*}{$\begin{array}{l}\text { Solder } \\
\text { material }\end{array}$} & \multicolumn{2}{|c|}{ CSES (before corrosion) } & \multicolumn{2}{|c|}{ CSI (before corrosion) } & \multicolumn{2}{|c|}{ CSES (after corrosion) } & \multicolumn{2}{|c|}{ CSI (after corrosion) } \\
\hline & $\begin{array}{l}\text { Elect. resisti. } \\
\quad(\mu \Omega \cdot \mathrm{cm})\end{array}$ & Std devi. & $\begin{array}{l}\text { Elect. resisti. } \\
\quad(\mu \Omega \cdot \mathrm{cm})\end{array}$ & Std devi. & $\begin{array}{l}\text { Elect. resisti. } \\
(\mu \Omega \cdot \mathrm{cm})\end{array}$ & Std devi. & $\begin{array}{c}\text { Elect. resisti. } \\
(\mu \Omega \cdot \mathrm{cm})\end{array}$ & Std devi. \\
\hline SAC305 & 0.001944 & $1.17 E-05$ & 0.001958 & $1.24 E-05$ & 0.001987 & $1.25 E-05$ & 0.001999 & $1.23 E-05$ \\
\hline SACX0307 & 0.001959 & $1.17 E-05$ & 0.001966 & $1.26 E-05$ & 0.001991 & $1.28 E-05$ & 0.002014 & $1.25 E-05$ \\
\hline $99 \mathrm{C}$ & 0.001969 & $1.18 E-05$ & 0.001989 & $1.28 E-05$ & 0.002006 & $1.29 E-05$ & 0.002016 & $1.27 E-05$ \\
\hline $\mathrm{SnPb}$ & 0.002011 & $1.19 E-05$ & 0.002024 & $1.29 E-05$ & 0.002048 & $1.30 E-05$ & 0.002066 & $1.30 E-05$ \\
\hline $\mathrm{Cu}$ substrate & 0.00171 & & 0.00171 & & 0.00171 & & 0.00171 & \\
\hline
\end{tabular}

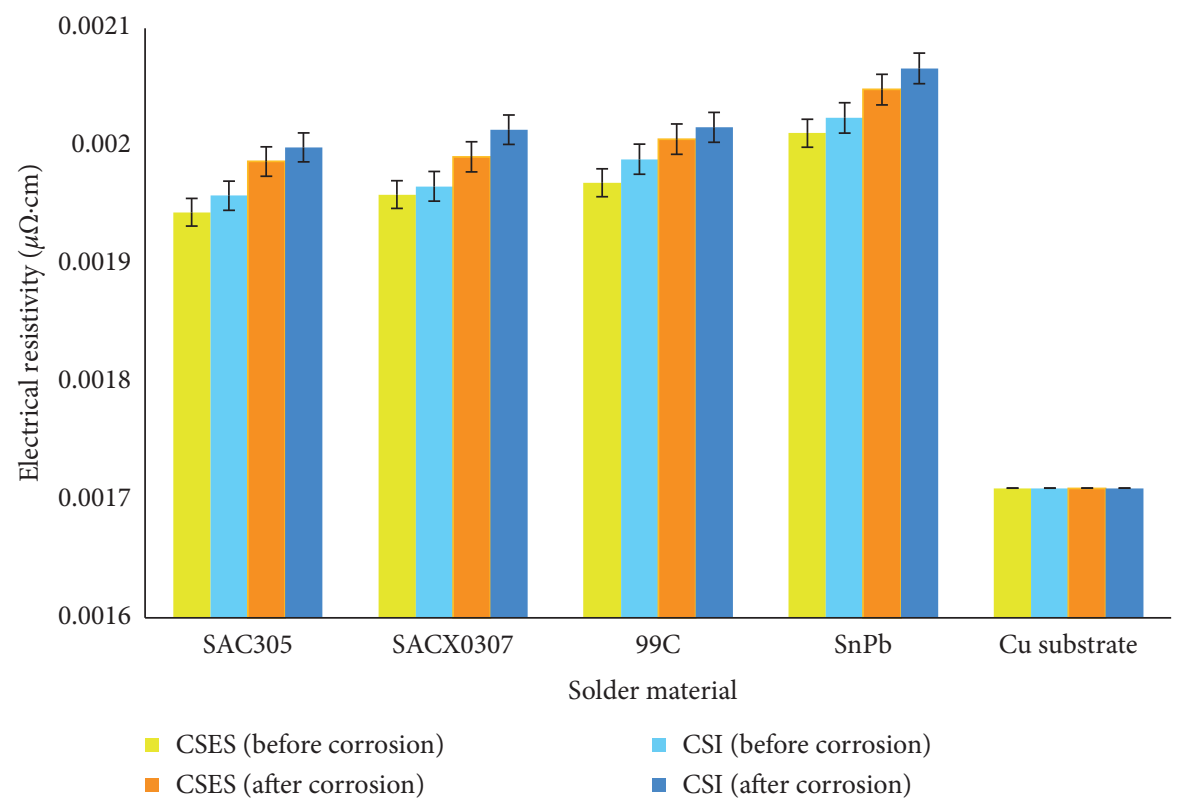

FIGURE 11: Plot of electrical resistivity of pure $\mathrm{Cu}$ and different lead-free and $\mathrm{SnPb}$ solder joints created using CSES and CSI methods (before and after corrosion). 


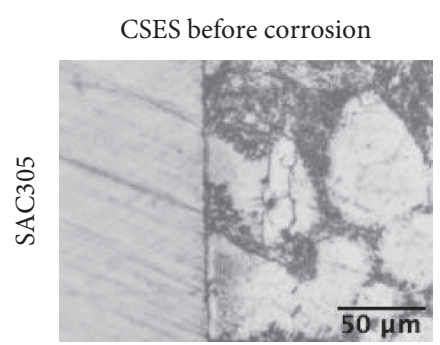

(a)

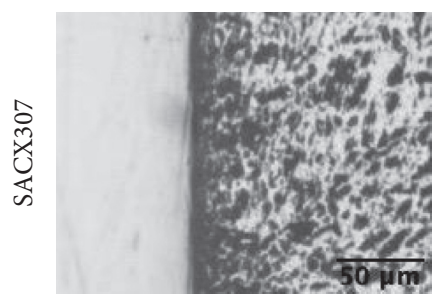

(e)

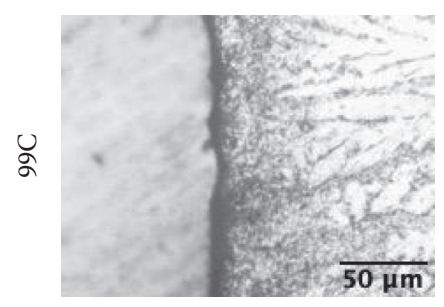

(i)

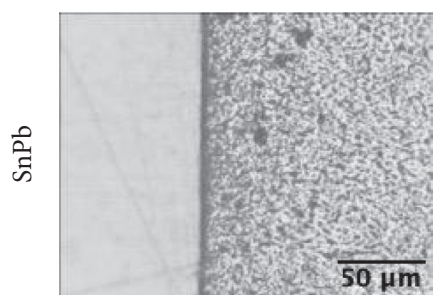

(m)
CSI before corrosion

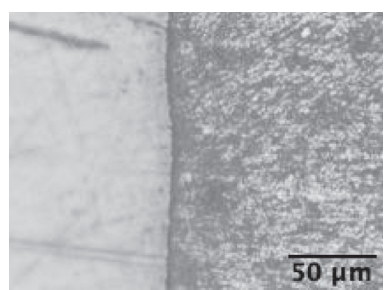

(b)

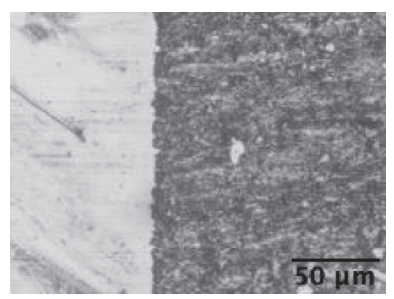

(f)

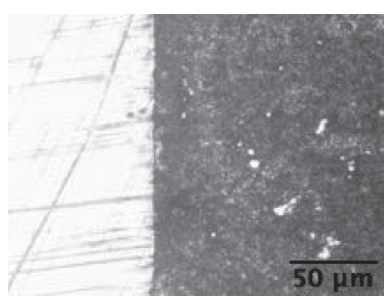

(j)

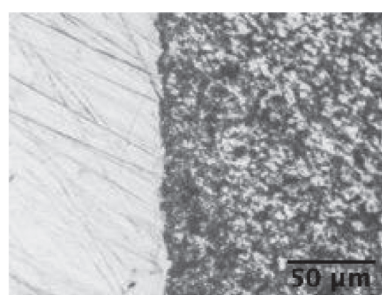

(n)
CSES after corrosion

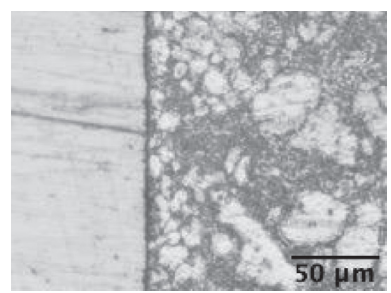

(c)

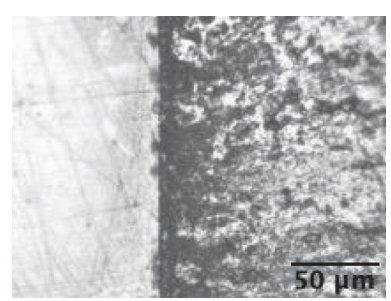

(g)

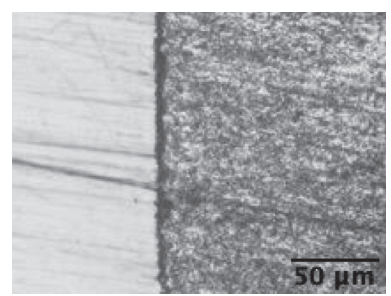

(k)

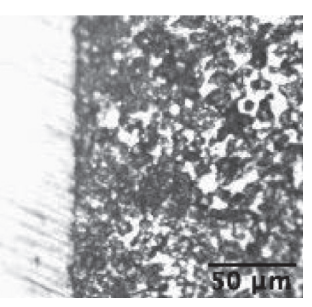

(o)
CSI after corrosion

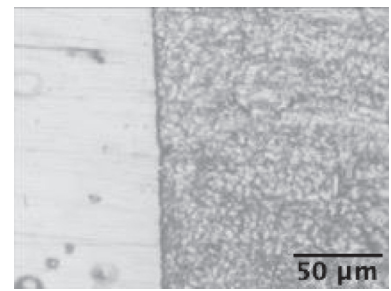

(d)

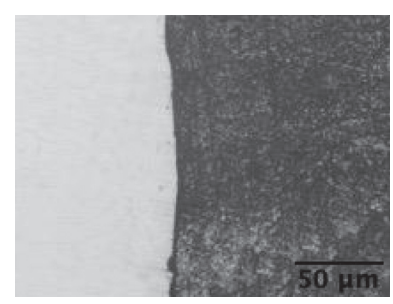

(h)

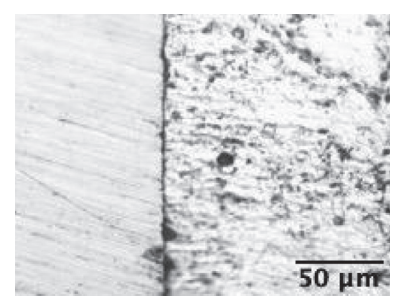

(1)

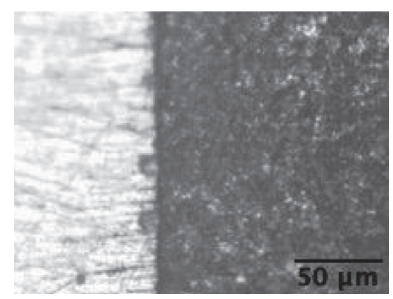

(p)

FIGURE 12: Representative optical micrographs showing microstructure evolution at solder joints of different lead-free and $\mathrm{SnPb}$ solder joints created using CSES and CSI methods (before and after corrosion).

solder joint compared with the $\mathrm{Cu} / 99 \mathrm{C} / \mathrm{Cu}$ CSI (before corrosion) solder joint were found to be reduced because of microporosity and severe interdendritic corrosion which were observed to have occurred in the solder joint (see Tables 2 and 3).

The microstructure of the $\mathrm{Cu} / \mathrm{SnPb} / \mathrm{Cu}$ CSES (before corrosion) solder joint shows globules and slightly dendritic structure in a eutectic matrix (see Figures $12(\mathrm{~m}), 13,14(\mathrm{~m})$ and $15(\mathrm{~m}))$.

As shown in Figures 12(n), 13(n), 14(n), and 15(n), the microstructure of the $\mathrm{Cu} / \mathrm{SnPb} / \mathrm{Cu} \mathrm{CSI}$ (before corrosion) solder joint shows globules and dendrites (lead-rich solid solution) in a eutectic matrix with microporosity. Microporosity observed led to reduction in the tensile and bending strength of the solder joint when compared with that of the
$\mathrm{Cu} / \mathrm{SnPb} / \mathrm{Cu} \mathrm{CSES}$ (before corrosion) solder joint (see Tables 2 and 3 ).

The microstructure of the $\mathrm{Cu} / \mathrm{SnPb} / \mathrm{Cu}$ CSES solder joint (after corrosion) shows globules and slightly dendritic of the lead-rich solid solution in a eutectic matrix (see Figures 12(o), 13(o), 14(o), and 15(o)). Interdendritic corrosion was observed in the solder joint, which reduced the tensile and bending strength of the solder joint compared with that of the $\mathrm{Cu} / \mathrm{SnPb} / \mathrm{Cu}$ CSES (before corrosion) solder joint (see Tables 2 and 3 ).

Globules and dendrites of the lead-rich solid solution in a eutectic matrix with microporosity were observed for the $\mathrm{Cu}$ / $\mathrm{SnPb} / \mathrm{Cu} \mathrm{CSI}$ (after corrosion) solder joint (see Figures 12(p), 13(p), 14(p), and 15(p)). Tensile and bending strength of the solder joint compared with that of the $\mathrm{Cu} / \mathrm{SnPb} / \mathrm{Cu} \mathrm{CSI}$ 
CSES

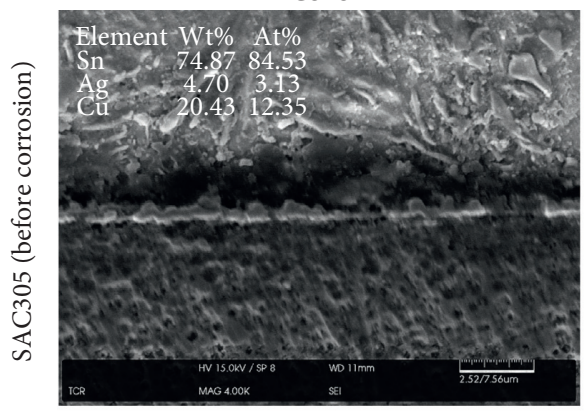

(a)

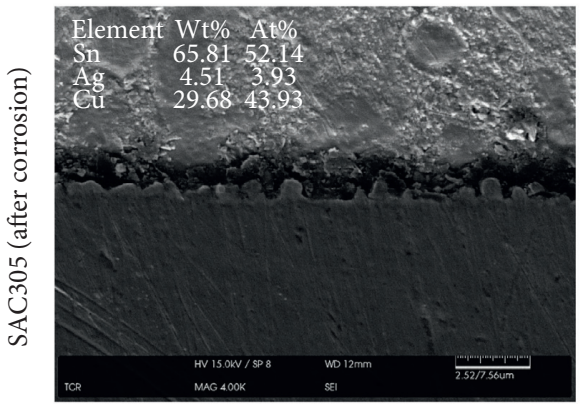

(c)

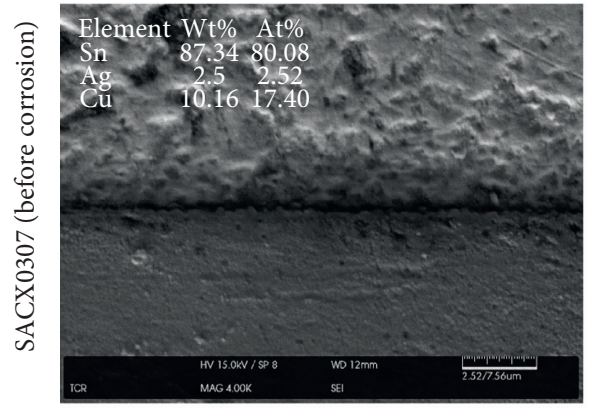

(e)

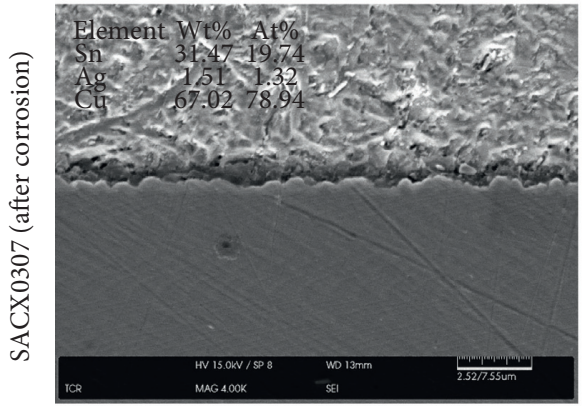

(g)

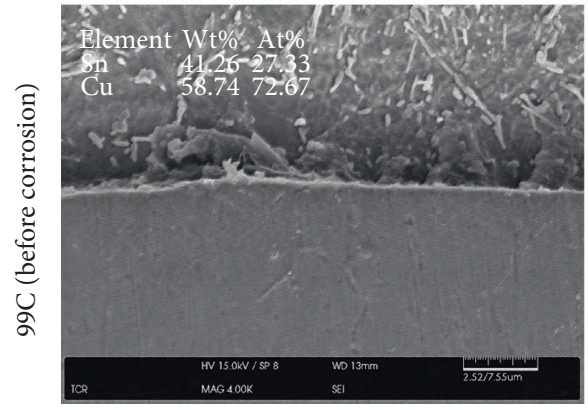

(i)
CSI

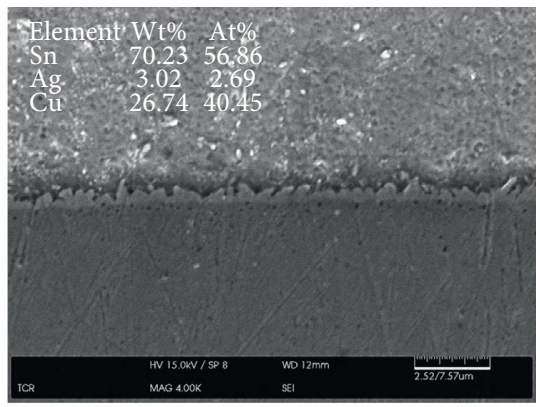

(b)

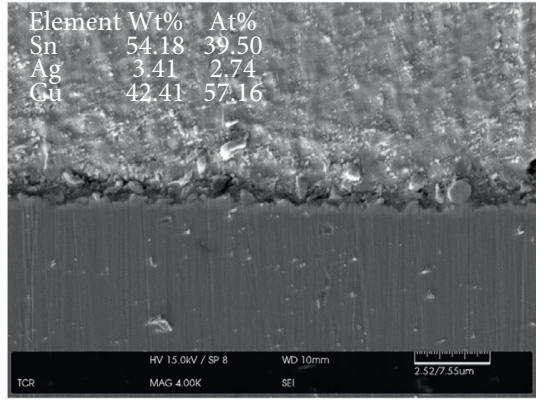

(d)

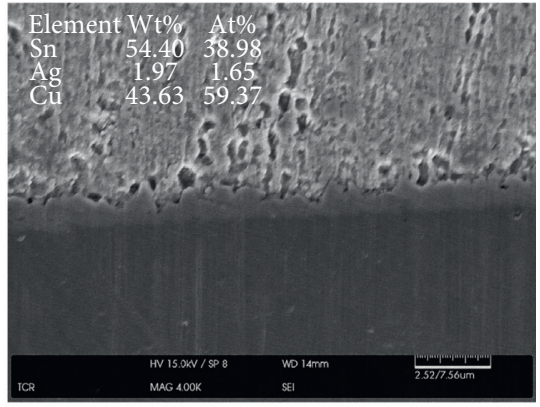

(f)

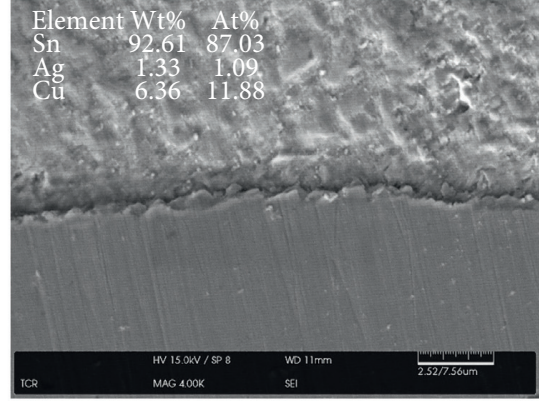

(h)

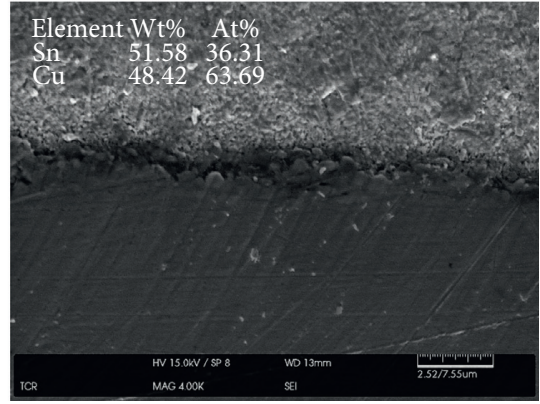

(j)

Figure 13: Continued. 
CSES

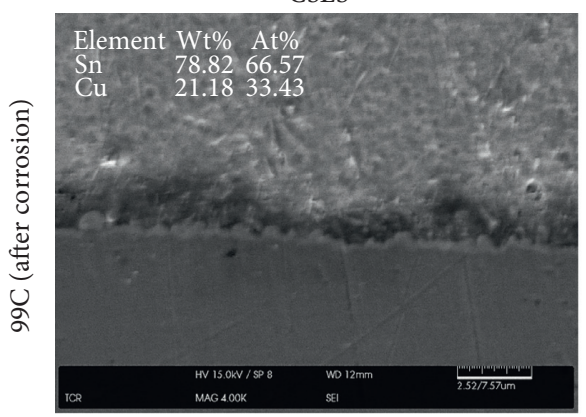

(k)

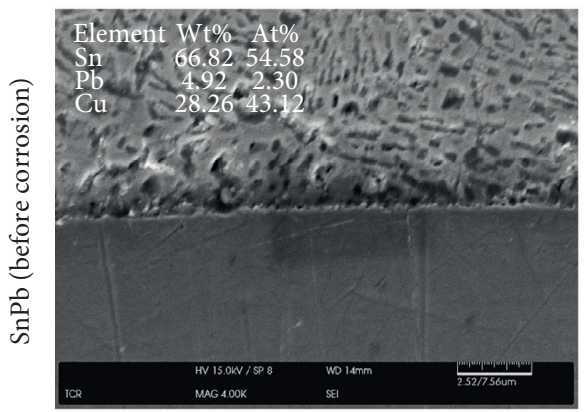

(m)

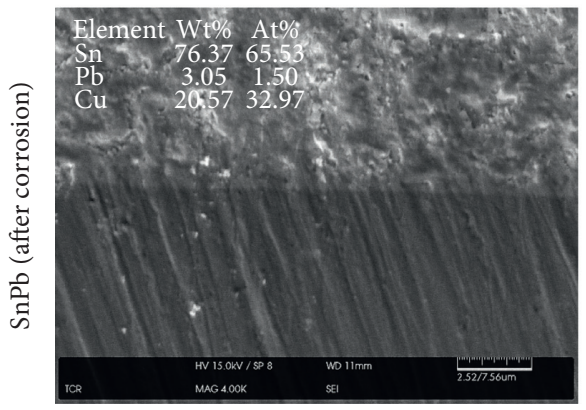

(o)
CSI

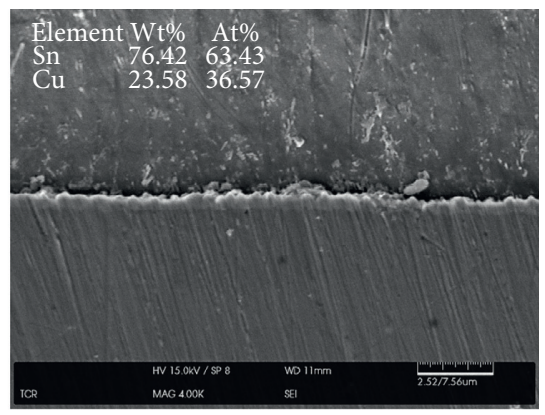

(1)

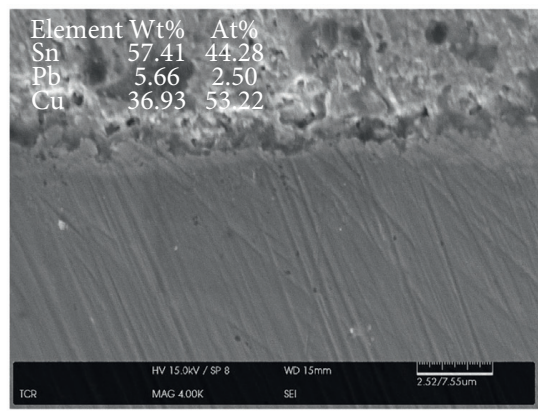

(n)

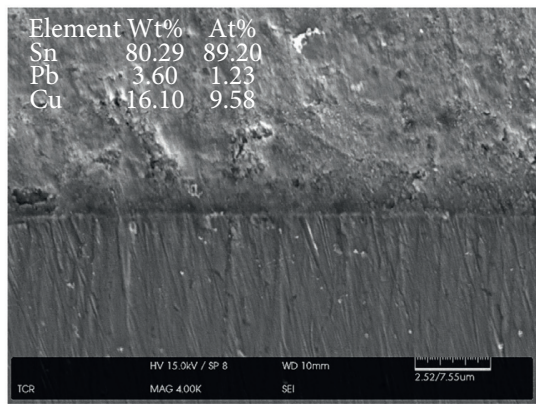

(p)

FIGURE 13: Representative SEM micrographs and EDS results at solder joints of different lead-free and SnPb solder joints created using CSES and CSI methods (before and after corrosion). Element wt.\% values are at intermetallic compounds (IMCs).

(before corrosion) solder joint were found to be reduced because of microporosity and interdendritic corrosion which were observed to have occurred in the solder joint (see Tables 2 and 3).

Overall results of microstructural characterization reveal that in the case of CSES joint, continuous heat was provided to join two substrates, which melts solder material faster but solidification requires more time compared to the CSI solder joint, resulting in the coarse microstructure. The coarsening was due to higher heat input. In CSES solders joints, heat input and flow were considered to be better when compared with that of CSI solder joints in view of fusion quality and improved mechanical properties.

As there was intermittent heat provided to join two substrates, in the case of CSI joints, which takes more time to melt and achieve faster solidification of the solder when compared to CSES solder joint, resulted in comparatively refined microstructure. The observations indicate that in the case of CSI joints, the finer microstructure was evolved due to less heat input and faster cooling rate in comparison to the coarser grained CSES joints.

Because of more homogenized heat input, the alloying element distribution and microstructure seem to be better in case of CSES joints. This is seen as the main reason why less corrosion is observed in case of CSES solder joints than CSI solder joints. Since corrosion resistance is related to solder chemical composition, its effect was observed in both CSES and CSI solder joints. But, CSES solder joints fared marginally better in corrosion resistance than CSI solder joints. However, both are susceptible to corrosion under similar conditions. As corrosion is the property of composition, improvement in chemical composition of solder material can improve corrosion resistance of solder joints.

Further, the results of microstructural examination using SEM on extruded CSES and CSI solder joints revealed no cracks or debonding at the interface which means the interfacial integrity was good (see Figures 13 and 15). Good 


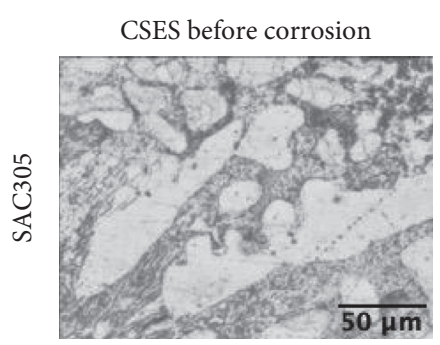

(a)

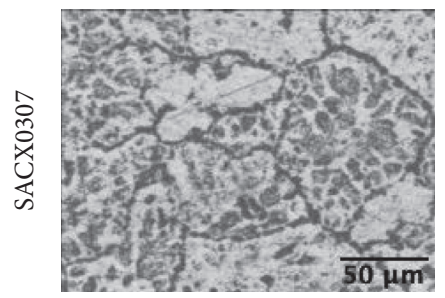

(e)

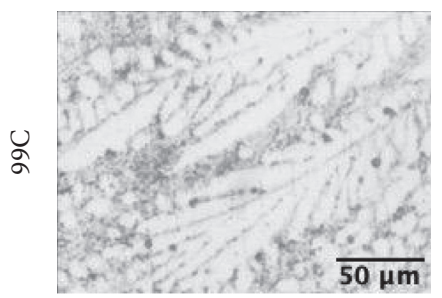

(i)

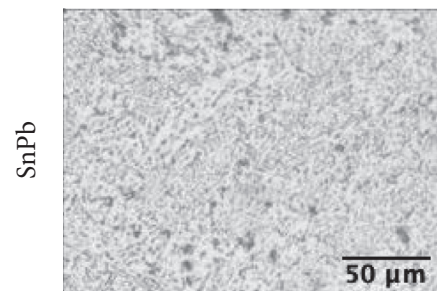

(m)
CSI before corrosion

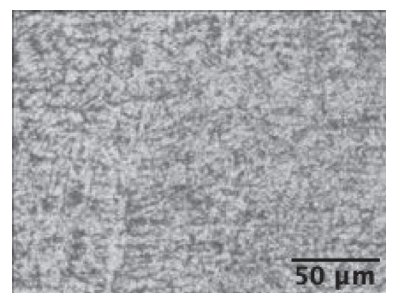

(b)

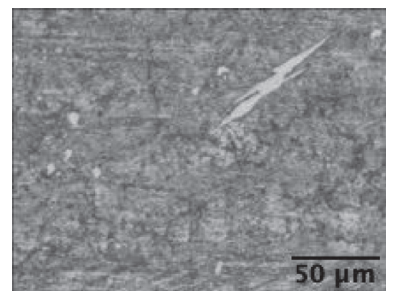

(f)

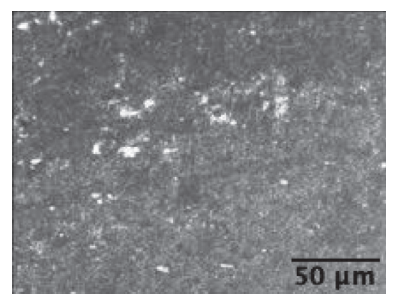

(j)

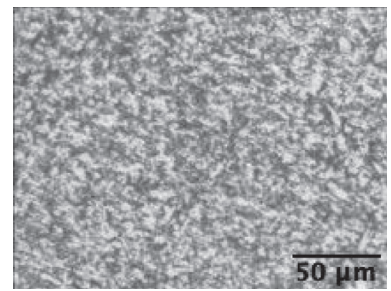

(n)
CSES after corrosion

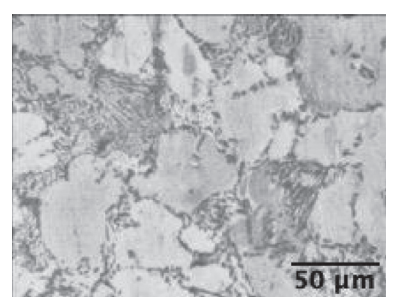

(c)

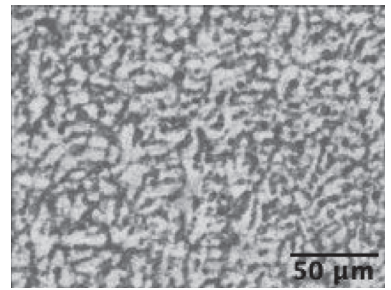

(g)

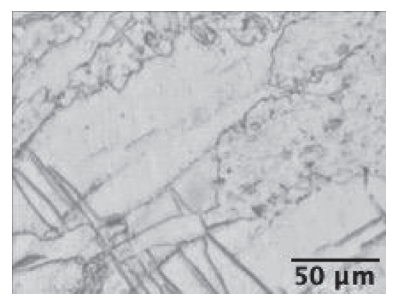

(k)

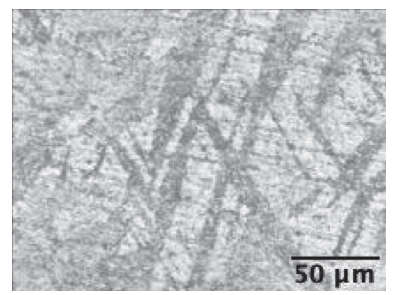

(o)
CSI after corrosion

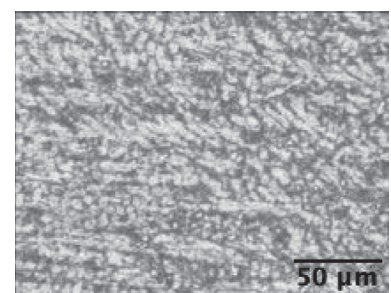

(d)

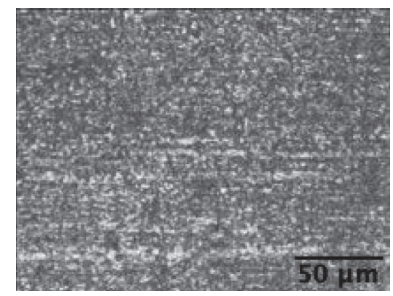

(h)

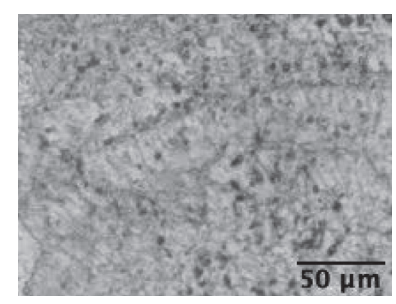

(1)

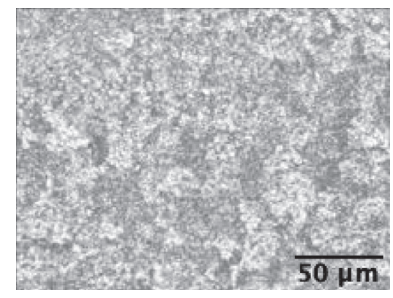

(p)

FIGURE 14: Representative optical micrographs showing microstructure evolution at solder portion of different lead-free and SnPb solder joints created using CSES and CSI methods (before and after corrosion).

bonding between the substrate and solder mostly depends on the integrity of the intermetallic compound (IMC) layer. The long-term reliability of solder joints depends on how, at the interface, IMCs are formed as reaction products between the solder and the substrate during soldering [38-42]. In this study, IMCs were clearly observed in $\mathrm{Cu} /$ SAC305/Cu solder joints (see Figures 13(a)-13(d)), Cu/ SACX0307/Cu solder joints (see Figures 13(e)-13(h)), Cu/ 99C/Cu solder joints (see Figures 13(i) $-13(\mathrm{l})$ ), and $\mathrm{Cu} /$ $\mathrm{SnPb} / \mathrm{Cu}$ solder joints (see Figures 13(m)-13(p)). Identical distribution of IMCs and suitable interfacial integrity are attributed as contributing factors that supported the increase in strength of the CSES and CSI solder joints. The IMCs formed in case of CSES (before and after corrosion) solder joints (see Figures 13(a), 13(c), 13(e), 13(g), 13(i), 13(k), 13(m), and 13(o)) had slightly less thickness than CSI (before and after corrosion) solder joints (see Figures 13(b), 13(d), 13(f), 13(h), 13(j), 13(l), 13(n), and 13(p), which reduced the brittleness in CSES joints thus making CSES solder joints marginally better in strength than CSI solder joints. This can be attributed to the melting and solidification of solder characteristics and better fusion quality in case of CSES solder joints when compared to CSI solder joints. EDS analysis results showed different elements in a solder joint as well as at IMCs for $\mathrm{Cu} / \mathrm{SAC} 305 /$ $\mathrm{Cu}, \mathrm{Cu} / \mathrm{SACX} 0307 / \mathrm{Cu}$, and $\mathrm{Cu} / 99 \mathrm{C} / \mathrm{Cu}$ and $\mathrm{Cu} / \mathrm{SnPb} / \mathrm{Cu}$ (before corrosion and after corrosion) solder joints. Elements' wt.\% and at.\% of intermetallic compounds (IMCs) and at the solder portion of the solder joint for different solder joints are shown in Figures 13 and 15, respectively. 
CSES

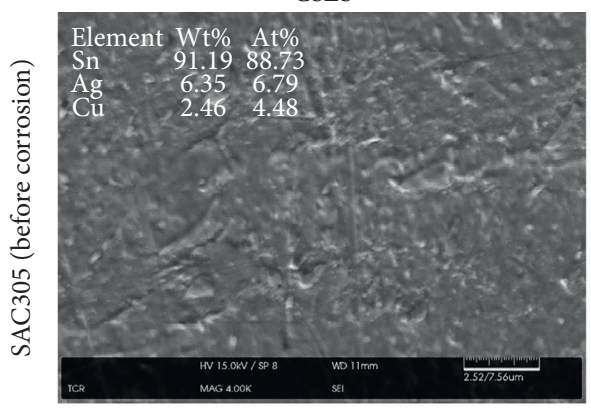

(a)

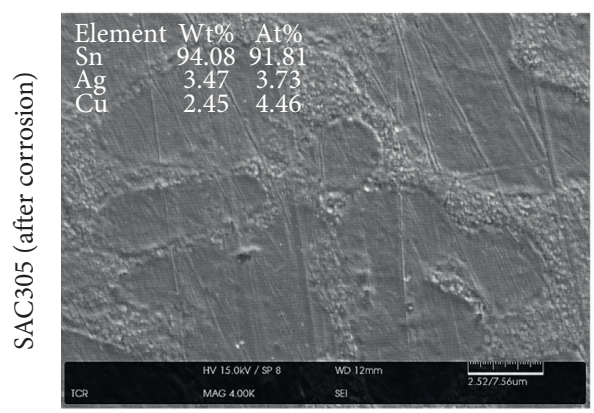

(c)

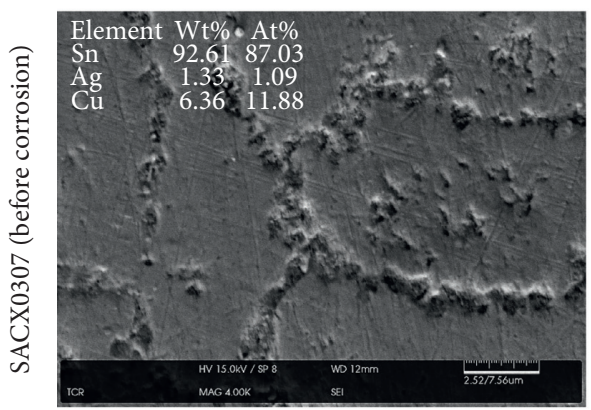

(e)

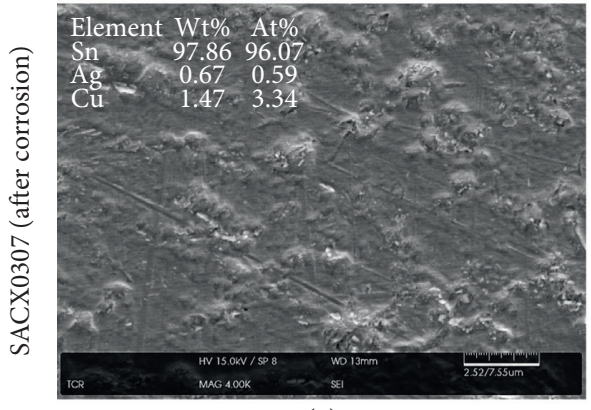

(g)

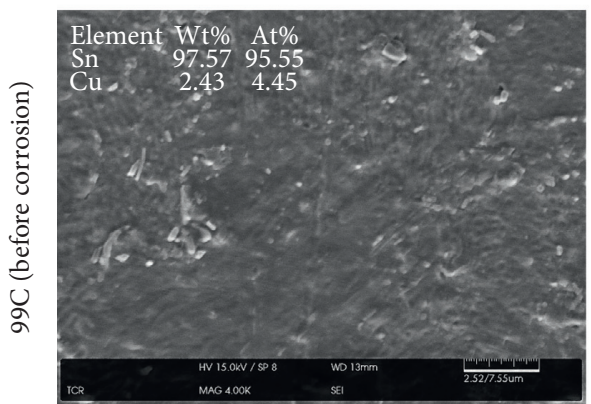

(i)
CSI

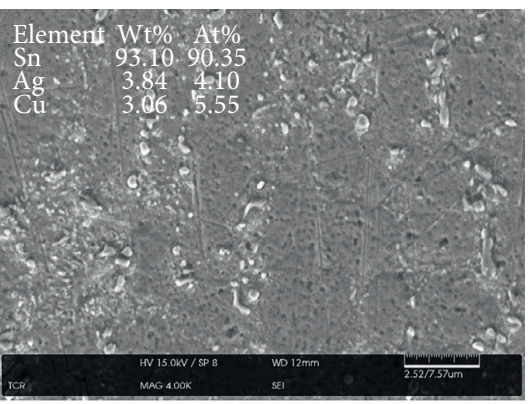

(b)

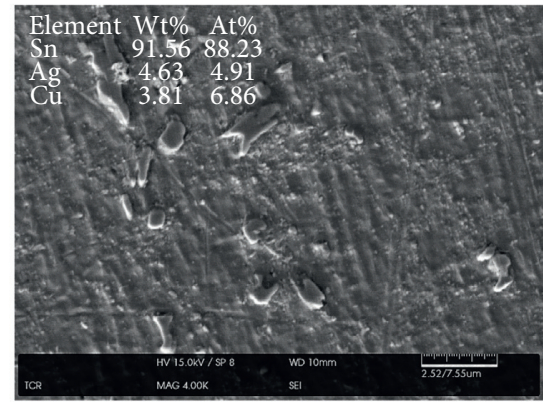

(d)

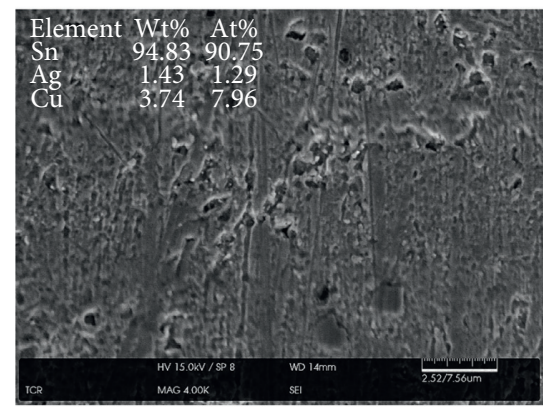

(f)

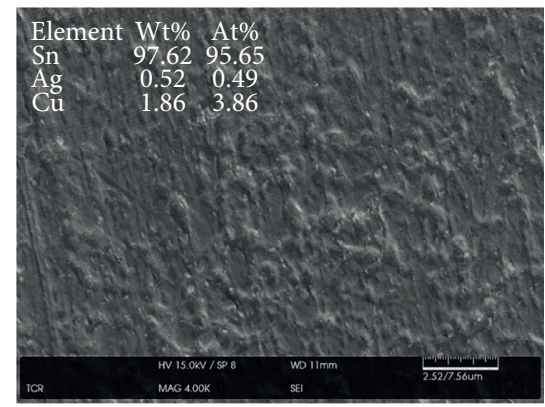

(h)

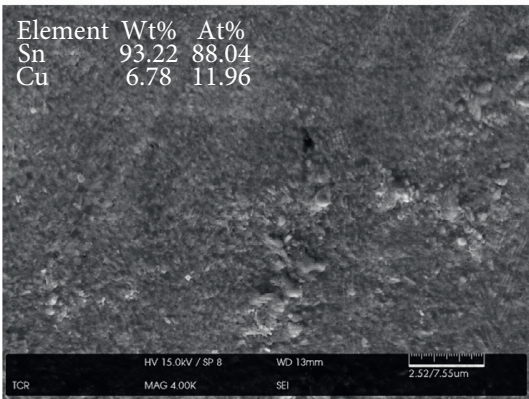

(j)

Figure 15: Continued. 
CSES

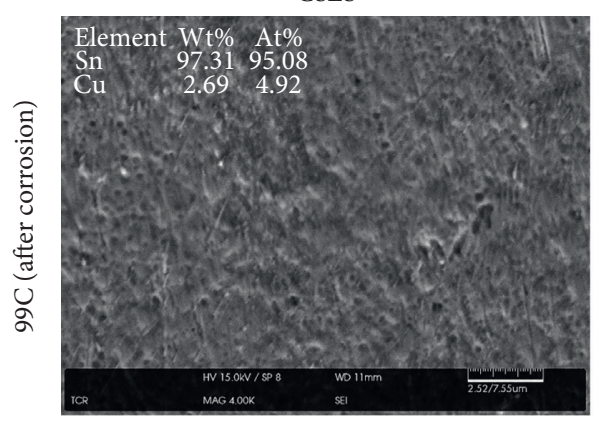

(k)

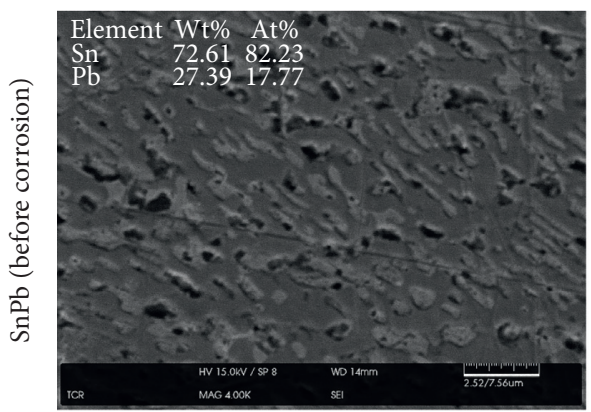

(m)

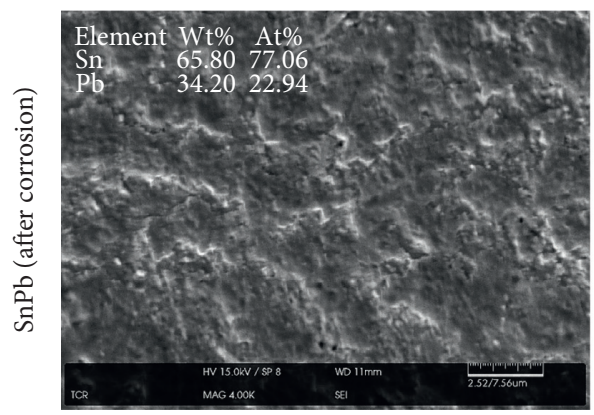

(o)

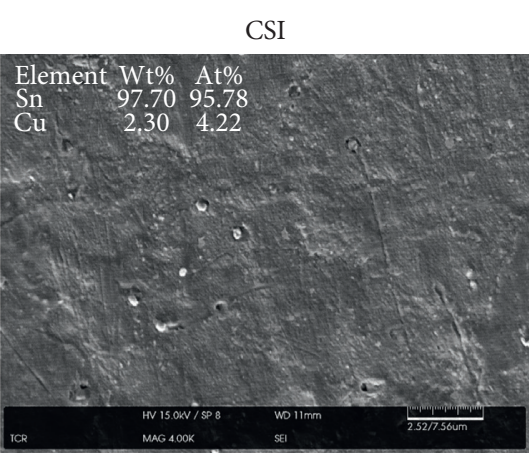

(1)

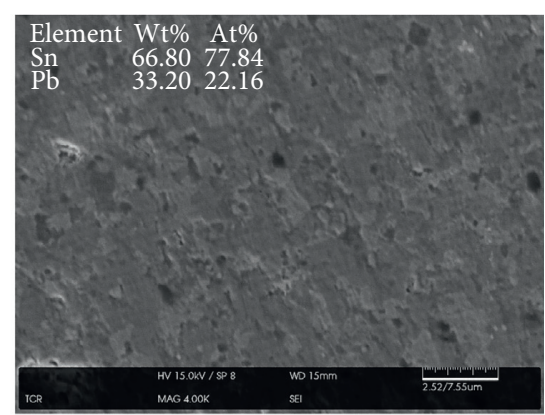

(n)

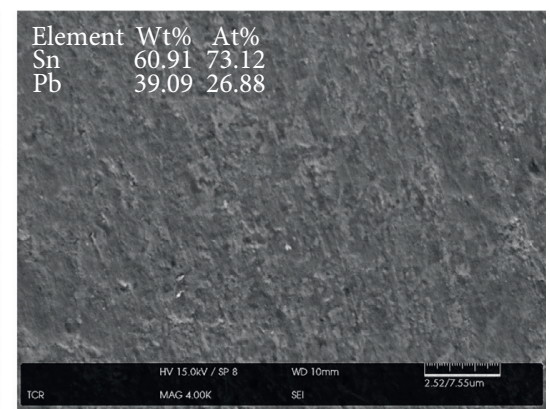

(p)

FIGURE 15: Representative SEM micrographs showing microstructure and EDS results at solder portion of different lead-free and SnPb solder joints created using CSES and CSI methods (before and after corrosion). Element wt.\% values are at solder portion of solder joints.

\section{Conclusions}

The following conclusion can be drawn from the present study:

(1) The results showed that the tensile response of CSES solder joints is almost equal to that of CSI solder joints.

(2) Bending/flexural strength of CSES solder joints was found to be comparable with CSI solder joints.

(3) Microhardness measurement of CSES and CSI solder joints was practically similar.

(4) Electrical resistivities of CSES solder joints were slightly better than that exhibited by CSI solder joints.

(5) For CSES and CSI solder joints, interfacial integrity was found to be good, as there were no cracks or debonding observed at the interface.
(6) The intermetallic compounds (IMCs) formed in case of CSES solder joints exhibited slightly less thickness than CSI solder joints, which reduced the brittleness in CSES solder joints.

(7) It was observed that after corrosion, the tensile strength, bending strength, and microhardness for CSES and CSI solder joints reduced. With corrosion, electrical resistivity for all the cases studied was found to increase slightly. The effect of corrosion on CSES and CSI solder joints was clearly seen in the microstructures.

(8) The results obtained proves CSES technique as green technology and an alternative to the CSI method.

\section{Data Availability}

The data can be made available to the interested researchers on request to the corresponding author. 


\section{Conflicts of Interest}

The authors declare that there are no conflicts of interest regarding the publication of this paper.

\section{References}

[1] P. D. Sonawane and V. K. Bupesh Raja, "Advances in lead-free solders," International Journal of Mechanical Engineering and Technology, vol. 10, no. 2, pp. 520-526, 2019.

[2] S. Cheng, C.-M. Huang, and M. Pecht, "A review of lead-free solders for electronics applications," Microelectronics Reliability, vol. 75, pp. 77-95, 2017.

[3] L. Zhang and K. N. Tu, "Structure and properties of lead-free solders bearing micro and nano particles," Materials Science and Engineering: R: Reports, vol. 82, no. 1, pp. 1-32, 2014.

[4] P. Zhang, S. Xue, J. Wang, P. Xue, S. Zhong, and W. Long, "Effect of nanoparticles addition on the microstructure and properties of lead-free solders: a review," Applied Sciences, vol. 9, no. 10, p. 2044, 2019.

[5] Q. Zhang, Investigations on Microstructure and Mechanical Properties of the $\mathrm{Cu} / \mathrm{Pb}$-Free Solder Joint Interfaces, Springer, Berlin, Germany, 2015.

[6] H. R. Kotadia, P. D. Howes, and S. H. Mannan, "A review: on the development of low melting temperature Pb-free solders," Microelectronics Reliability, vol. 54, no. 6-7, pp. 1253-127, 2014.

[7] O. Fornaro, "Directional solidification of $\mathrm{Sn}-\mathrm{Cu}_{6} \mathrm{Sn}_{5}$ in situ composites," Advances in Materials Science and Engineering, vol. 2019, Article ID 9210713, 8 pages, 2019.

[8] W. R. Osório, E. S. Freitas, J. E. Spinelli, and A. Garcia, "Electrochemical behavior of a lead free $\mathrm{Sn}-\mathrm{Cu}$ solder alloy in $\mathrm{NaCl}$ solution," Corrosion Science, vol. 80, pp. 71-81, 2014.

[9] L. Sun and L. Zhang, "Properties and microstructures of SnAg-Cu-X lead-free solder joints in electronic packaging," Advances in Materials Science and Engineering, vol. 2015, Article ID 639028, 16 pages, 2015.

[10] X. Hu, T. Xua, L. M. Keer, Y. Li, and X. Jiang, "Microstructure evolution and shear fracture behavior of aged $\mathrm{Sn} 3 \mathrm{Ag} 0.5 \mathrm{Cu} / \mathrm{Cu}$ solder joints," Materials Science and Engineering: A, vol. 673, pp. 167-177, 2016.

[11] F. Yang, L. Zhang, Z. Liu, S. Zhong, J. Ma, and L. Bao, "Properties and microstructures of Sn-Bi-X lead-free solders," Advances in Materials Science and Engineering, vol. 2016, Article ID 9265195, 16 pages, 2016.

[12] S. Li, Y. Liu, H. Zhang, H. Cai, F. Sun, and G. Zhang, "Microstructure and hardness of SAC305 and SAC305-0.3Ni solder on $\mathrm{Cu}$, high temperature treated $\mathrm{Cu}$, and graphenecoated Cu substrates," Results in Physics, vol. 11, pp. 617-622, 2018.

[13] M. F. M. Nazeri, M. Z. Yahaya, A. Gursel, F. Cheani, M. N. Masri, and A. A. Mohamad, "Corrosion characterization of Sn-Zn solder: a review," Soldering \& Surface Mount Technology, vol. 31, no. 1, pp. 52-67, 2019.

[14] M. Wang, J. Wang, and W. Ke, "Corrosion behavior of Sn3.0Ag-0.5Cu lead-free solder joints," Microelectronics Reliability, vol. 73, pp. 69-75, 2017.

[15] M. Thirugnanasambandam, S. Iniyan, and R. Goic, "A review of solar thermal technologies," Renewable and Sustainable Energy Reviews, vol. 14, no. 1, pp. 312-322, 2010.

[16] P. D. Sonawane and V. K. Bupesh Raja, "An overview of concentrated solar energy and its applications," International Journal of Ambient Energy, vol. 39, no. 8, pp. 898-903, 2018.
[17] A. J. Francis and V. K. Bupesh Raja, "An overview of concentrated solar power (CSP) and its applications," International Journal of Applied Engineering and Research, vol. 10, no. 5, pp. 1755-1761, 2015.

[18] C. Sierra and A. J. Vázquez, "High solar energy concentration with a Fresnel lens," Journal of Materials Science, vol. 40, no. 6, pp. 1339-1343, 2005.

[19] D. I. Pantelis, P. Psyllaki, and C. Sarafoglou, "Surface alloying on cast iron using concentrated solar energy," Fonderie, vol. 1, pp. 1-13, 2002.

[20] P. D. Sonawane and V. K. Bupesh Raja, "Concentrated solar energy in materials processing," International Journal of Ambient Energy, pp. 1-7, 2018.

[21] R. Leutz and A. Suzuki, Nonimaging Fresnel Lenses: Design and Performance of Solar Concentrators, Springer, Berlin, Germany, 2001.

[22] P. D. Sonawane and V. K. Bupesh Raja, "Novel "concentrated solar energy soldering (CSES) technique"-a feasibility study," in Proceedings of the IEEE 5th International Conference on Science, Technology, Engineering and Mathematics (ICONSTEM 2K19), pp. 401-407, Chennai, India, March 2019.

[23] P. D. Sonawane and V. K. Bupesh Raja, "Portable solar welding kit," Indian patent 201721009049, 2017.

[24] M. F. M. Nazeri and A. A. Mohamad, "Effect of exposure to alkaline solution on Sn-9Zn solder joints," Journal of Materials Processing Technology, vol. 219, pp. 164-172, 2015.

[25] Y. Zhou, Microjoining and Nanojoining, Woodhead Publishing Limited, Cambridge, UK, 2008.

[26] S. M. L. Nai, J. Wei, and M. Gupta, "Effect of carbon nanotubes on the shear Strength and electrical resistivity of a lead-free solder," Journal of Electronic Materials, vol. 37, no. 4, pp. 515-522, 2008.

[27] R. Koleňák and I. Kostolný, "Study of direct bonding ceramics with metal using Sn2La solder," Advances in Materials Science and Engineering, vol. 2015, Article ID 269167, 13 pages, 2015.

[28] P. B. Thompson, R. Johnson, and S. P. V. Nadimpalli, "Effect of temperature on the fracture behavior of $\mathrm{Cu} / \mathrm{SAC} 305 / \mathrm{Cu}$ solder joints," Engineering Fracture Mechanics, vol. 199, pp. $730-738,2018$.

[29] G. Khatibi, A. Betzwar Kotas, and M. Lederer, "Effect of aging on mechanical properties of high temperature $\mathrm{Pb}$-rich solder joints," Microelectronics Reliability, vol. 85, pp. 1-11, 2018.

[30] M. E. Alam and M. Gupta, "Development of high strength Sn$\mathrm{Mg}$ solder alloys with reasonable ductility," Electronic $\mathrm{Ma}$ terials Letters, vol. 9, no. 5, pp. 575-585, 2013.

[31] M. Drienovsky, E. Michalcova, M. Pekarcikova et al., "Induction soldering of coated conductor high-temperature superconducting tapes with lead-free solder alloys," IEEE Transactions on Applied Superconductivity, vol. 28, no. 4, pp. 1-5, 2018.

[32] M. E. Alam and M. Gupta, "Development of extremely ductile lead-free $\mathrm{Sn}$-Al solders for futuristic electronic packaging applications," Electronic Materials Letters, vol. 10, no. 2, pp. 515-524, 2014.

[33] X. Chen, A. Singh, S. Konovalov, J. R. Hirsch, and K. Wang, "Corrosion of materials after advanced surface processing, joining, and welding," International Journal of Corrosion, vol. 2018, Article ID 3569282, 3 pages, 2018.

[34] J. C. Guerrero, D. H. Camacho, O. Mokhtari, and H. Nishikawa, "Corrosion and leaching behaviours of Sn$0.7 \mathrm{Cu}-0.05 \mathrm{Ni}$ lead-free solder in 3.5 wt. $\% \mathrm{NaCl}$ solution," International Journal of Corrosion, vol. 2018, Article ID 6580750, 11 pages, 2018. 
[35] M. Z. Nurwahida, M. M. Mukridz, A. M. Ahmad, and F. M. N. Muhammad, "Corrosion properties of SAC305 solder in different solution of $\mathrm{HCl}$ and $\mathrm{NaCl}$," IOP Conference Series: Materials Sciences and Engineering, vol. 318, Article ID 012004, 2018.

[36] M. A. Fazal, N. K. Liyana, S. Rubaiee, and A. Anas, "A critical review on performance, microstructure and corrosion resistance of $\mathrm{Pb}$ free solders," Measurement, vol. 134, pp. 897-907, 2019.

[37] A. K. Gain and L. Zhang, "High-temperature and humidity change the microstructure and degrade the material properties of tin-silver interconnect material," Microelectronics Reliability, vol. 83, pp. 101-110, 2018.

[38] L. Yang, S. Li, W. Song, X. Wang, H. Zhang, and F. Sun, "Interfacial reaction, microstructure and mechanical properties of Sn58Bi solder joints on graphene-coated $\mathrm{Cu}$ substrate," Results in Physics, vol. 13, Article ID 102256, 2019.

[39] X. Bi, X. Hu, Q. Li, and Y. Li, "Theoretical and experimental investigations on mechanical properties of $\mathrm{Co}_{1-x} \mathrm{Ni}_{x} \mathrm{Sn}_{2}$ intermetallic compounds," Results in Physics, vol. 14, Article ID 102439, 2019.

[40] R. Tian, C. Hang, Y. Tian, and L. Zhao, "Growth behavior of intermetallic compounds and early formation of cracks in Sn$3 \mathrm{Ag}-0.5 \mathrm{Cu}$ solder joints under extreme temperature thermal shock," Materials Science and Engineering: A, vol. 709, pp. 125-133, 2018.

[41] L. M. Lee and A. A. Mohamad, "Interfacial reaction of Sn-Ag$\mathrm{Cu}$ lead-free solder alloy on $\mathrm{Cu}$ : a review," Advances in Materials Science and Engineering, vol. 2013, Article ID 123697, 11 pages, 2013.

[42] J. B. Libot, J. Alexis, O. Dalverny, L. Arnaud, P. Milesi, and F. Dulondel, "Microstructural evolutions of Sn-3.0Ag-0.5Cu solder joints during thermal cycling," Microelectronics Reliability, vol. 83, pp. 64-76, 2018. 